\title{
Hedgehog-mediated mesenchymal-epithelial interactions modulate hepatic response to bile duct ligation
}

\author{
Alessia Omenetti ${ }^{1, *}$, Liu Yang ${ }^{1, *}$, Yin-Xiong Li ${ }^{1,2}$, Shannon J McCall ${ }^{3}$, Youngmi Jung ${ }^{1}$, Jason K Sicklick ${ }^{4}$, \\ Jiawen Huang ${ }^{1}$, Steve Choi ${ }^{1}$, Ayako Suzuki ${ }^{1}$ and Anna Mae Diehl ${ }^{1}$
}

In bile duct-ligated (BDL) rodents, as in humans with chronic cholangiopathies, biliary obstruction triggers proliferation of bile ductular cells that are surrounded by fibrosis produced by adjacent myofibroblastic cells in the hepatic mesenchyme. The proximity of the myofibroblasts and cholangiocytes suggests that mesenchymal-epithelial crosstalk promotes the fibroproliferative response to cholestatic liver injury. Studying BDL mice, we found that bile duct obstruction induces activity of the Hedgehog $(\mathrm{Hh})$ pathway, a system that regulates the viability and differentiation of various progenitors during embryogenesis. After BDL, many bile ductular cells and fibroblastic-appearing cells in the portal stroma express $\mathrm{Hh}$ ligands, receptor and/or target genes. Transwell cocultures of an immature cholangiocyte line that expresses the Hh receptor, Patched (Ptc), with liver myofibroblastic cells demonstrated that both cell types produced Hh ligands that enhanced each other's viability and proliferation. Further support for the concept that Hh signaling modulates the response to BDL was generated by studying PtcLacZ mice, which have an impaired ability to constrain Hh signaling due to a heterozygous deficiency of Ptc. After BDL, PtcLacZ mice upregulated fibrosis gene expression earlier than wild-type controls and manifested an unusually intense ductular reaction, more expanded fibrotic portal areas, and a greater number of lobular necrotic foci. Our findings reveal that adult livers resurrect developmental signaling systems, such as the Hh pathway, to guide remodeling of the biliary epithelia and stroma after cholestatic injury.

Laboratory Investigation (2007) 87, 499-514. doi:10.1038/labinvest.3700537; published online 5 March 2007

KEYWORDS: cholangiocyte; cholestasis; hedgehog; hepatic stellate cells; biliary fibrosis

Cholangiocytes, specialized epithelial cells that line the biliary tree, are the primary target of injury in a heterogeneous group of genetic and acquired biliary disorders that are collectively termed cholangiopathies. ${ }^{1}$ Patients with cholangiopathies experience morbidity and some eventually succumb to liver-related mortality. Fortunately, both acute and chronic cholangiocyte damage generally evoke a compensatory repair response. ${ }^{2}$ The latter initially involves replication of surviving mature bile duct cells, proliferation of immature bile ductular cells along the edges of portal triads, periportal accumulation of alpha-smooth muscle actin ( $\alpha$-SMA)-positive myofibroblastic cells derived from resident portal fibroblasts and injury-activated myofibroblastic hepatic stellate cells (HSC), as well as some degree of portal fibrosis. ${ }^{2-10}$ During chronic cholangiocyte injury, the fibro-proliferative response often extends into the hepatic parenchyma, bridging adjacent portal areas and culminating in biliary cirrhosis, rather than reconstructing a healthy biliary tree. ${ }^{1}$ Thus, chronic cholestatic liver damage results, at least in part, from unsuccessful repair of biliary injury.

It is not well understood why biliary regeneration fails to keep pace with cholangiocyte loss during chronic biliary injury. Insight into this issue might suggest novel treatments to improve recovery from bile duct injury. To model biliary repair responses, bile duct ligation (BDL) is often performed in mice or rats to induce protracted biliary obstruction and chronic cholestasis. ${ }^{1,10}$ In BDL rodents, as in humans with chronic cholangiopathies, biliary obstruction triggers

\footnotetext{
${ }^{1}$ Division of Gastroenterology, Department of Medicine, Duke University Medical Center, Durham, NC, USA; ${ }^{2}$ Pediatrics and Cell Biology, Department of Medicine, Duke University Medical Center, Durham, NC, USA; ${ }^{3}$ Department of Pathology, Duke University Medical Center, Durham, NC, USA and ${ }^{4}$ Department of Surgery, Johns Hopkins University School of Medicine, Baltimore, MD, USA

Correspondence: Dr AM Diehl, MD, Division of Gastroenterology, Duke University Medical Center, Room 1073, GSRB \#1 595 LaSalle Street, Durham, NC 27710, USA. E-mail: annamae.diehl@duke.edu

*These authors contributed equally to this work.

Received 15 December 2006; revised 17 January 2007; accepted 21 January 2007
} 
proliferation of bile ductular cells that are typically surrounded by septae of collagen matrix produced by adjacent myofibroblastic cells. ${ }^{10}$ The temporal and spatial proximity of these responses have prompted speculation that crosstalk between myofibroblastic cells in the hepatic mesenchyme and epithelial bile ductular cells promotes expansion of both populations, as well as progressive fibrosis. ${ }^{1,8}$ Although many of the specific paracrine signals involved remain to be elucidated, evidence that reactive cholangiocytes actively stimulate the fibrogenic response has been reported. ${ }^{1,8}$ For example, platelet-derived growth factor (PDGF)-BB released from ductular cells during biliary injury has been shown to induce myofibroblastic gene expression in resident portal fibroblasts, ${ }^{9}$ promote proliferation of lobular $\mathrm{HSC}^{5}$ and attract lobular myofibroblastic HSC into portal tracts, ${ }^{6}$ thereby expanding populations of myofibroblastic cells around injured bile ducts.

Here, we investigate the converse, that is, how mesenchymal-epithelial interactions between myofibroblastic cells and cholangiocytes might promote cholangiocyte accumulation. Studying BDL mice, we found that bile duct obstruction induced mRNA expression of the Hedgehog (Hh) pathway, a system that is known to regulate the viability and differentiation of various types of progenitors. ${ }^{11-14}$ Immunohistochemistry of BDL livers demonstrated that bile ductular cells and fibroblastic cells in adjacent stroma expressed Hh ligands, receptor, and target genes. Moreover, the fibroproliferative response to BDL appeared to be enhanced in transgenic mice with increased Hh activity. Subsequent transwell cocultures of myofibroblastic HSC and cholangiocytes showed that both cell types produced and responded to Hh ligands. Antibody neutralization studies indicated that the myofibroblastic mesenchymal cells produced Hh ligands that enhanced the viability and proliferation of bile ductular epithelial cells, and vice versa (ie, that cholangiocyte-derived Hh ligands promoted growth of the myofibroblastic cells). To our knowledge, this is the first evidence that the Hh pathway, which is well accepted to regulate morphogenesis of various tissues during fetal life, ${ }^{15-22}$ plays a role in adult liver repair. This discovery opens a novel area for future research that might help to clarify the pathogenesis of chronic cholangiopathies and lead to novel therapies to improve recovery from bile duct injury.

\section{MATERIALS AND METHODS}

\section{Animals and Experimental Design}

Healthy wild-type (WT) C57BL6 mice were obtained from Jackson Laboratories (Bar Harbor, ME, USA). Adult (aged 8-12 weeks) mice underwent either BDL or sham surgery ( $n=12$ mice/group). Additional PtcLacZ reporter mice and their WT litter mates were obtained from PA Beachy (Johns Hopkins University, Baltimore, MD, USA). ${ }^{23}$ At 8 weeks of age, these mice were also subjected to either BDL or sham operation ( $n=12$ per each group). Animals were killed 1-2 weeks after surgery; blood and liver samples were obtained. ${ }^{24}$
Animal studies were approved by the Duke University Medical Center Institutional Animal Care and Use Committee as set forth in the 'Guide for the Care and Use of Laboratory Animals' published by the National Institutes of Health.

\section{Morphometry}

Collagen staining of formalin-fixed liver sections with picrosirus red was assessed by morphometric analysis (MetaView software, Universal Imaging Corp, Downtownington, PA, USA). Ten randomly chosen $\times 20$ fields/section were evaluated for each mouse. ${ }^{24}$ Portal tract size was also compared in WT and PtcLacZ mice after BDL. Using AudioVision software (Zeiss, Germany), the longest dimension of each portal tract (PT) was measured on one representative hematoxylin and eosin (H\&E)-stained liver section from each mouse. At least seven PTs were evaluated/section and the average PT longitudinal axis length was calculated for each animal. Mean \pm s.e.m. results for the PtcLacZ and WT groups were compared ( $n=6$ mice/group). Necrotic foci were also counted in $10 \times 100$ fields on each H\&E-stained section.

\section{Hydroxyproline Assay}

Hepatic hydroxyproline content was quantified colorimetrically in flash frozen liver samples. ${ }^{24}$ Concentrations were calculated from a standard curve prepared with high purity hydroxyproline (Sigma, St Louis, MO, USA) and expressed as mg hydroxyproline/g liver.

\section{Immunohistochemistry}

Liver tissue was fixed in formalin and embedded in paraffin. Immunohistochemical staining to detect $\alpha$-SMA and pancytokeratin (DAKO Corporation, Carpinteria, CA, USA) was performed using the DAKO Envision System (DAKO Corporation, Carpinteria, CA, USA) according to the manufacturer's protocol. Indian Hedgehog (Ihh) and Gli2 (Santa Cruz Biotechnology Inc., Santa Cruz, CA, USA) and Patched (Ptc; AbCam, Cambridge, MA, USA) immunostaining were performed as described. ${ }^{25}$ Specimens were incubated with the peroxidase-labeled polymer conjugated to goat anti-mouse or anti-rabbit immunoglobulins (diluted $1: 2$ in phosphatebuffered saline) for $5 \mathrm{~min}$. For Ptc immunostaining, anti-goat HRP conjugated was used as secondary antibody. The tissue was counterstained with Aqua Hematoxylin-INNOVEX (Innovex Biosciences, Richmond, CA, USA). Negative controls for Ihh, Ptc, and Gli-2 staining included BDL liver specimens exposed to $1 \%$ bovine serum albumin instead of the respective primary antibodies. Mouse intestine was used as a positive control for each of these antigens. ${ }^{25}$ Cells that stained intensely brown, were considered positive for Ihh, Ptc, or Gli-2.

Little, if any, immunoreactivity for any of the Hh pathway antigens was demonstrated in sham-operated mice. After BDL, however, many brown cells were localized to portal tracts (PT). Therefore, to derive mean numbers of positive 
and negative cells/PT, positively stained and negatively stained cells were counted in at least seven PTs/section in randomly selected mice (three mice/group).

\section{Cell Culture}

A clonally derived rat myofibroblastic hepatic stellate cell line (HSC 8B) was obtained from M Rojkind, GWU (Washington DC, USA), ${ }^{26}$ and cultured as described. ${ }^{27}$ In some experiments, HSC 8B were treated with $50 \mathrm{nM}$ epidermal growth factor (EGF, R\&D Systems Minneapolis, MN, USA) for $16 \mathrm{~h}$; then Sonic Hedgehog (Shh) and Ihh mRNA expression was evaluated by real-time reverse transcription-polymerase chain reaction (RT-PCR). The murine Cholangiocyte 603B $\operatorname{line}^{28}$ was provided by G Gores (Mayo Clinic, Rochester, MN, USA), and maintained as described. ${ }^{29}$ The murine hepatic progenitor cell line (OV) was from Dr BE Petersen (University of Florida; Gainesville, FL, USA). ${ }^{30}$ Primary mouse hepatocytes were isolated as described. ${ }^{26}$ RNA from OV and hepatocytes were used as positive controls for immature and mature hepatic epithelial cells, respectively.
HSC and cholangiocyte lines were cultured alone or in a Transwell insert coculture system for 3-6 days, using 4- $\mu \mathrm{m}$ pore size polyester (PET) inserts (Corning Inc., Corning, NY, USA). All coculture experiments were performed with cholangiocytes in the bottom well, and HSC in the top well (1:1 ratio), using 5\% serum-supplemented RPMI-1640 medium (Gibco/BRL, Grand Island, NY, USA) $10 \mathrm{mM}$ HEPES, penicillin $100 \mathrm{IU} / \mathrm{mL}$ and streptomycin $100 \mu \mathrm{g} / \mathrm{mL}$ (Gibco/BRL, Grand Island, NY, USA). Cells were plated at a density of $5 \times 10^{3}$ cells/well in six-well plates, and cultured overnight in monoculture systems. Insert chambers with HSC were then transferred into coculture systems and cocultured for 3 or 6 days.

To evaluate the role of $\mathrm{Hh}$ ligands, 5E1 Hh-neutralizing antibody (University of Iowa Developmental Studies Hybridoma Bank, Iowa City, IA, USA) or IgG1 isotype control antibody (R\&D Systems, Minneapolis, MN, USA) at concentration $10 \mu \mathrm{g} / \mathrm{ml}^{31,32}$ were added to HSC culture-conditioned medium; cholangiocytes were cultured in this medium for an additional 3 days. Proliferation and apoptosis were then assayed, and compared to control/naïve mono-

Table 1 Primers sequences

\begin{tabular}{|c|c|c|c|}
\hline Gene & Forward sequence & Reverse sequence & Product size $(b p)$ \\
\hline $\operatorname{Shh}^{\mathrm{a}}$ & 5'-CTGGCCAGATGTITCTGGT-3' & 5'-TAAAGGGGTCAGCTाTाGG-3' & 117 \\
\hline $\mathrm{Shh}^{\mathrm{b}}$ & 5'-CTGGCCAGATGTITCTGGT-3' & 5'-TAAAGGGGTCAGCTाTाGG-3' & 117 \\
\hline $\operatorname{lhh}^{\mathrm{a}}$ & 5'-CCGAACCTTCATCTTGGTG-3' & $5^{\prime}$-ACAGATGGAATGCGTGTGAA-3' & 124 \\
\hline $\mathrm{Ihh}^{\mathrm{b}}$ & 5'-CCCTCGTCTTGGTGTAGAG-3' & $5^{\prime}$-GAATCGCAGTCAGAGCTAGC-3' & 105 \\
\hline $\mathrm{Ptc}^{\mathrm{a}}$ & 5'-ATGCTCCTITCCTCCTGAAACC--3' & $5^{\prime}$-TGAACTGGGCAGCTATGAAGTC-3' & 168 \\
\hline $\mathrm{Ptc}^{\mathrm{b}}$ & 5'-ATGCTCCTITCCTCCTGAAACC-3' & 5'-TGAACTGGGCAGCTATGAAGTC-3' & 168 \\
\hline $\mathrm{Smo}^{\mathrm{a}}$ & 5'-GCCTGGTGCTTATTGTGG-3' & 5'-GGTGGTTGCTCTTGATGG-3' & 75 \\
\hline $\mathrm{Smo}^{\mathrm{b}}$ & 5'-GCCTGGTGCTTATTGTGG-3' & 5'-GGTGGTTGCTCTTGATGG-3' & 75 \\
\hline $\mathrm{Gli}^{\mathrm{a}}$ & 5'-AACTCCACAGGCACACAGG-3' & 5'-GCTCAGGCTTCTCCTCTCTC-3' & 79 \\
\hline $\mathrm{Gli}^{\mathrm{b}}$ & 5'-AACTCCACGAGCACACAGG-3' & 5'-GCTCAGGTTTCTCCTCTCTC-3' & 79 \\
\hline $\mathrm{Gli}^{\mathrm{a}}$ & 5'-CCATTCATAAGCGGAGCAAG-3' & 5'-CCAGGTCTTCCTTGAGATCG-3' & 105 \\
\hline $\mathrm{Gli}^{\mathrm{b}}$ & 5'-CCATCCATAAGCGGAGCAAG-3' & 5'-CCAGATCTTCCTTGAGATCAG-3' & 105 \\
\hline $\mathrm{Gli}^{\mathrm{a}}$ & 5'-GCTCTTCAGCAAGTGGTTCC-3' & 5'-CTGTCGGCTTAGGATCTGTTG-3' & 122 \\
\hline $\mathrm{Gli}^{\mathrm{b}}$ & $5^{\prime}$-GTTCTTCAGCAAGTGGTTCC-3' & 5'-CTGTCGGCTTAGGATCTGTTG-3' & 122 \\
\hline GUS $S^{a}$ & 5'-GCAGTTGTGTGGGTGAATGG-3' & 5'-GGGTCAGTGTGTTGTTGATGG-3' & 142 \\
\hline GUS ${ }^{b}$ & 5'-GCAGTTGTGTGGGTGAATGG-3' & 5'-GGGTCAGTGTGTTGTTGATGG-3' & 142 \\
\hline CK-19 ${ }^{\mathrm{a}}$ & 5'-CATGGTTCTTCTTCAGGTAGGC-3' & 5'-GCTGCAGATGACTTCAGAACC-3' & 174 \\
\hline$A Q P-1^{a}$ & 5'-CTGCAGAGGCTCACTCTGTG-3' & $5^{\prime}$-CCCAGGCAGAAACTGAGAAG-3' & 446 \\
\hline NCAM $^{a}$ & $5^{\prime}$-GATCAGGGGCATCAAGAAAA-3' & $5^{\prime}$-GGAGGCTTCACAGGTCAGAG-3' & 475 \\
\hline$C-k_{i t}{ }^{a}$ & 5'- TATGCGTGTGGGTAGGTTGT-3' & 5'-GAAAACCGTGAAGGCAACAT-3' & 430 \\
\hline $\mathrm{Mpk}^{\mathrm{a}}$ & $5^{\prime}$-CGTGAGATGCTGAAGGAGATG-3' & $3^{\prime}$-GCAACAGGACGGTAGAGAATG-3' & 155 \\
\hline Albumin ${ }^{a}$ & 5'-AGTTGGGGTTGACACCTGAG-3' & 5'-AGTTGGGGTTGACACCTGAG-3' & 464 \\
\hline
\end{tabular}

${ }^{a}$ Mus musculus species specific.

${ }^{\mathrm{b}}$ Rattus norvegicus species specific. 
culture. All experiments were repeated at least three times. A similar approach was then used to assess the impact of cholangiocyte-derived Hh ligands on HSC growth.
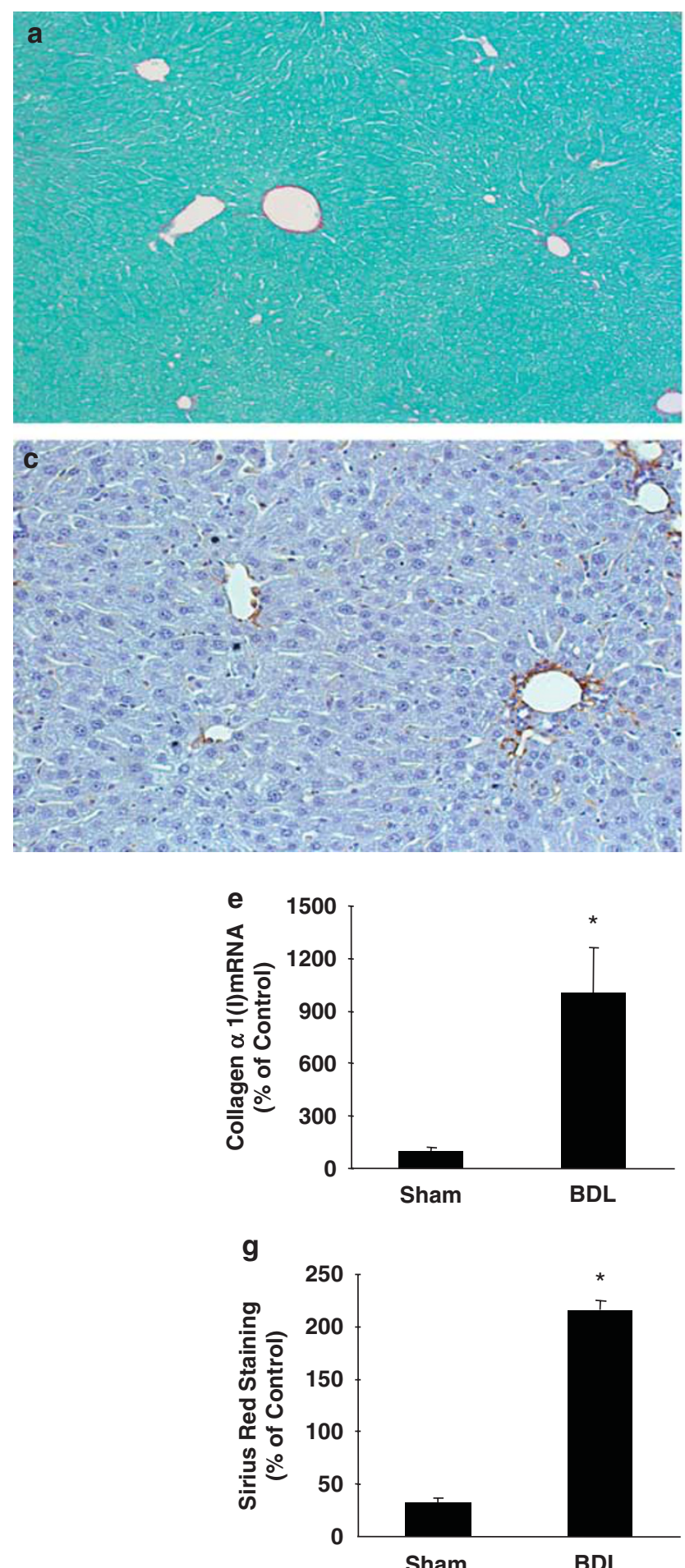

\section{Cell Viability Assay}

Cells were harvested from either the bottom or top well of six-well plates after 3-6 days of culture, and transferred in
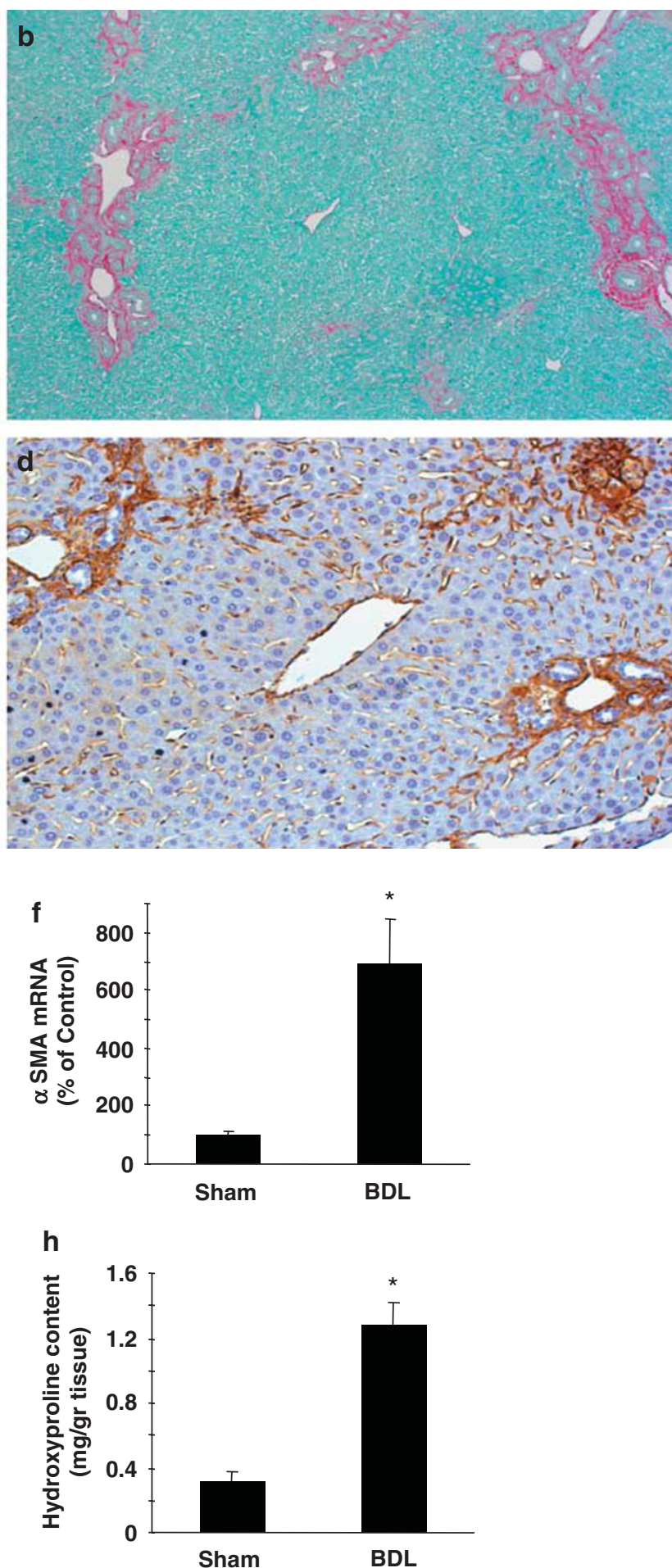

Figure 1 Effects of bile duct ligation (BDL) on liver fibrosis. Histology from representative sham-operated control (a, c) and BDL (b, d) mice 2 weeks after surgery. Sirius red staining at $\times 200$ of magnification $(\mathbf{a}, \mathbf{b})$; $\alpha$-smooth muscle actin ( $\alpha$ SMA) staining at $\times 200$ of magnification (c, d). RT-PCR analysis of collagen $\alpha 1$ (i) (e) and $\alpha$ SMA mRNA (f). Quantification of Sirius red-stained collagen fibrils (g) and hydroxyproline content (h). Data are displayed as mean \pm s.e.m. of six control mice and six treated mice $\left({ }^{*} P<0.05 \%\right.$ vs sham-operated control). 
equal volume to three different 96 -well plates. Cell viability was measured with the Cell Counting Kit-8 (Dojindo Molecular Technologies, Gaithersburg, MD, USA). ${ }^{33}$ All the experiments were repeated at least three times.

\section{Cell Proliferation Assay}

Cell proliferation was evaluated with the Cell proliferation ELISA BrdU immunoassay (Roche, Mannheim, Germany), as per the manufacturer's instructions. All the experiments were repeated at least three times.

\section{Caspases 3/7 Activity}

Apoptotic activity was assayed in parallel using the Apo-ONE Homogeneous Caspase 3/7 Apoptosis Assay (Promega, Madison, WI, USA), according to the vendor's instructions. ${ }^{32}$ All the experiments were repeated at least three times.

A FLUOstar OPTIMA microplate reader (BMG Labtech, Durham, NC, USA) was used for all absorbance, luminescence, and fluorescence measurements.

\section{Two-Step Real-Time RT-PCR and Conventional RT-PCR}

Total RNA was extracted from cells, liver, or brain using TRIzol (Invitrogen, Carlsbad, CA, USA), followed by RNasefree DNase I treatment (Qiagen, Valencia, CA, USA). RNA was reverse transcribed to cDNA templates using random primer and Superscript RNase H-reverse transcriptase (Invitrogen, Carlsbad, CA, USA) and amplified.

For semiquantitative QRT-PCR, 1.5\% of the first-strand reaction was amplified using iQ-SYBR Green Supermix (BioRad), an iCycler iQ Real-Time Detection System, and specific oligonucleotide primers for target sequences, as well as the $\beta$-glucuronidase (Gus) housekeeping gene. For QRT-PCR parameters were as follows: denaturating at $95^{\circ} \mathrm{C}$ for $3 \mathrm{~min}$, followed by 40 cycles of denaturing at $95^{\circ} \mathrm{C}$ for $10 \mathrm{~s}$ and annealing-extension at the optimal primers temperatures for
60 s. Threshold cycles $\left(C_{\mathrm{t}}\right)$ were automatically calculated by the iCycler iQ Real-Time Detection System. Target gene levels in the cells are presented as a ratio to levels detected in the corresponding control cells according to the $\Delta \Delta C_{\mathrm{t}}$ method.

For conventional PCR, after $2 \mathrm{~min}$ at $94^{\circ} \mathrm{C}, 30$ cycles of amplification were performed as follows: denaturating at $94^{\circ} \mathrm{C}$ for $30 \mathrm{~s}$, annealing at $55^{\circ} \mathrm{C}$ for $30 \mathrm{~s}$, extension at $68^{\circ} \mathrm{C}$ for $1 \mathrm{~min}$. Amplicon products were then separated by electrophoresis on a $2.0 \%$ agarose gel buffered with $0.5 \times \mathrm{TBE}$. Primer sequences are listed in Table 1.

\section{Statistical Analysis}

All the results are expressed as mean \pm s.e., unless indicated otherwise. Comparisons between groups were performed using the Student's $t$-test. Significance was accepted at the 5\% level.

\section{RESULTS}

\section{Hh Signaling Increases after Bile Duct Ligation}

As expected, BDL induced ductular proliferation, accumulation of $\alpha$-SMA-expressing myofibroblastic cells, and deposition of collagen around proliferating bile ductular cells (Figure 1a-d). By 2 weeks, there was more than a sixfold increase in collagen and $\alpha$-SMA mRNA levels (Figure 1e and f), and a three- to fourfold increase in the hepatic content of Sirius red fibrils and hydroxyproline (Figure $1 \mathrm{~g}$ and $\mathrm{h}$ ). Hepatic expression of EGF, a known mitogen for mature cholangiocytes, ${ }^{34}$ also increased after BDL (Figure 2a). In other parts of the gastrointestinal tract, EGF stimulates production of Hh ligands. ${ }^{35} \mathrm{Hh}$ ligands generally enhance the viability of epithelial progenitor cells ${ }^{12,14}$ and promote the morphogenesis of ductular structures. ${ }^{36}$

We recently reported that myofibroblastic HSCs produce Hh ligands that function as autocrine viability factors. ${ }^{32}$ Therefore, we used quantitative real-time PCR to determine
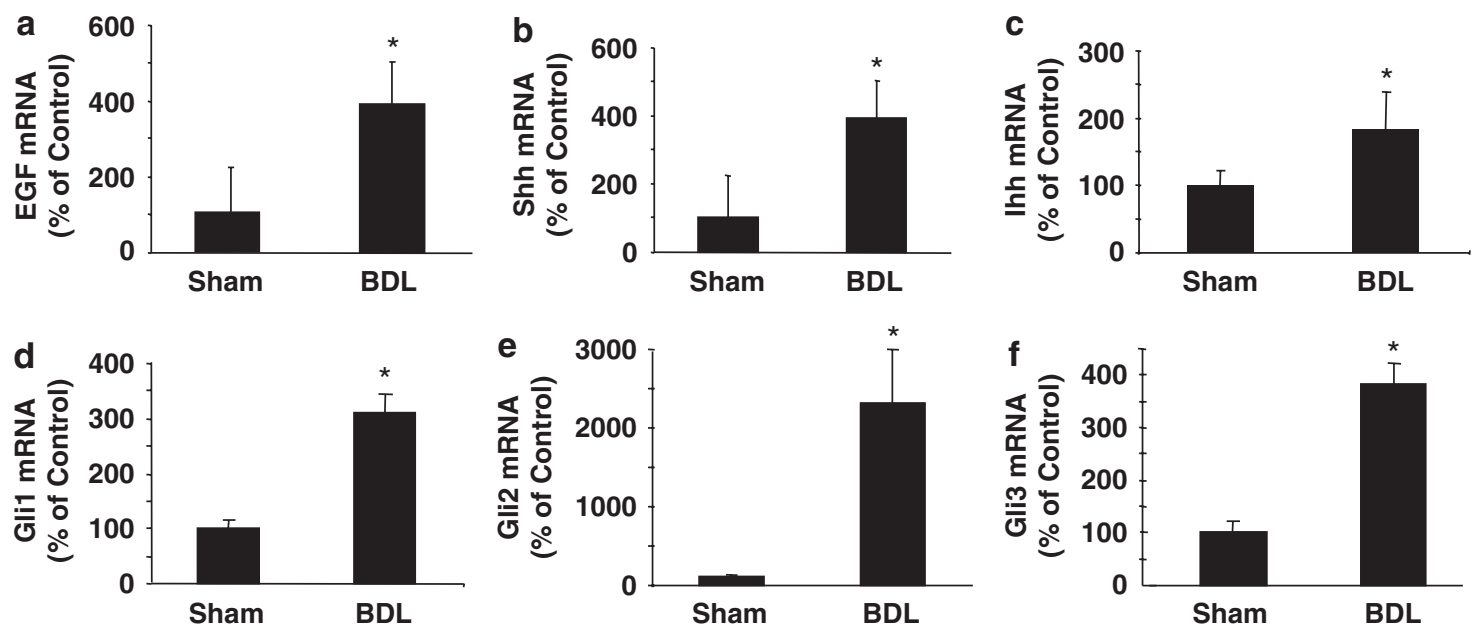

Figure 2 Effects of BDL on Hh pathway. Quantitative real-time RT-PCR analysis of mRNA from sham-operated control $(n=6)$ and BDL mice $(n=6)$ at 2 weeks postoperation. (a) EGF, (b) Shh, (c) Ihh, (d) Gli-1, (e) Gli-2, (f) Gli-3. Mean \pm s.e.m. $\left({ }^{\star} P<0.05 \%\right.$ vs sham control). 
if increases in EGF were accompanied by induction of Shh or Ihh expression in BDL livers. Indeed, we found that hepatic mRNA expression of both ligands increased about two- to threefold within 2 weeks of BDL (Figure 2b and c). Increases in the expression of Hh ligands were accompanied by induction of Hh-target genes, including the Gli family of transcription factors (Figure $2 \mathrm{~d}-\mathrm{f}$ ). Induction of Gli-2 was particularly robust, resulting in almost 20 times more Gli2 mRNA in the livers of BDL mice compared to sham-operated controls (Figure 2e).

Consistent with these mRNA data, immunohistochemistry demonstrated little, if any, hepatic expression of Hh ligands
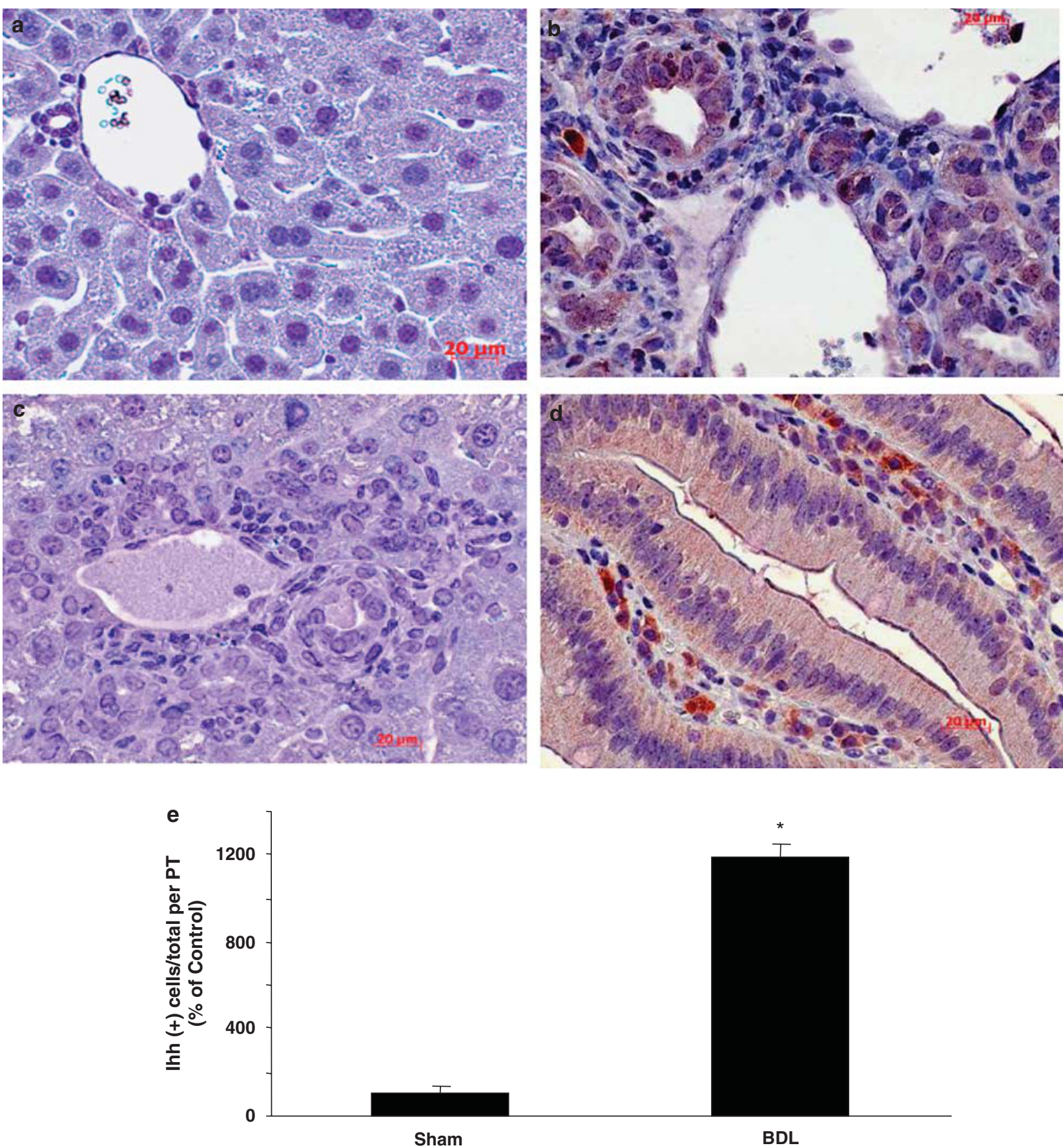

Figure $3 \mathrm{lhh}$ immunohistochemistry. Liver sections from representative mice at 1 week postsurgery: (a) sham-operated control, (b) BDL mouse, (c) negative control, that is, section from BDL mouse processed without primary anti-Ihh antibody, (d) positive control, that is, intestine from control mouse demonstrating expected $\mathrm{Ihh}(+)$ brown cells. $(\mathbf{e}) \mathrm{Ihh}(+)$ and $\mathrm{Ihh}(-)$ cells were counted in all portal tracts (PTs) in seven randomly selected fields/section in three mice that were randomly selected from each group. Results are expressed as mean \pm s.e.m. $\mathrm{lhh}(+)$ cells/total cells per PT. ${ }^{\star P}<0.05$ vs sham-operated control. Original magnification $\times 630$. 
in sham-operated mice (Figure 3a and e), but revealed considerable expression of Hh ligands by both stromal cells and bile ductular cells after BDL, with strongest and most consistent Ihh staining in the latter cell type (Figure $3 \mathrm{~b}$ and e). After BDL, some bile ductular cells and stromal cells also exhibited Ptc immunoreactivity (Figure $4 \mathrm{~b}$ and e), whereas little Ptc staining was noted in sham-operated controls (Figure 4a and e). Immunohistochemistry also failed to demonstrate much Gli-2 in sham-operated controls (Figure 5a and e), but showed intense nuclear staining for Gli-2 in many bile ductular cells and stromal cells in portal areas following BDL (Figure $5 \mathrm{~b}$ and e). Overall, BDL increased the numbers of cells expressing Hh-related proteins by 4 to 10 -fold.
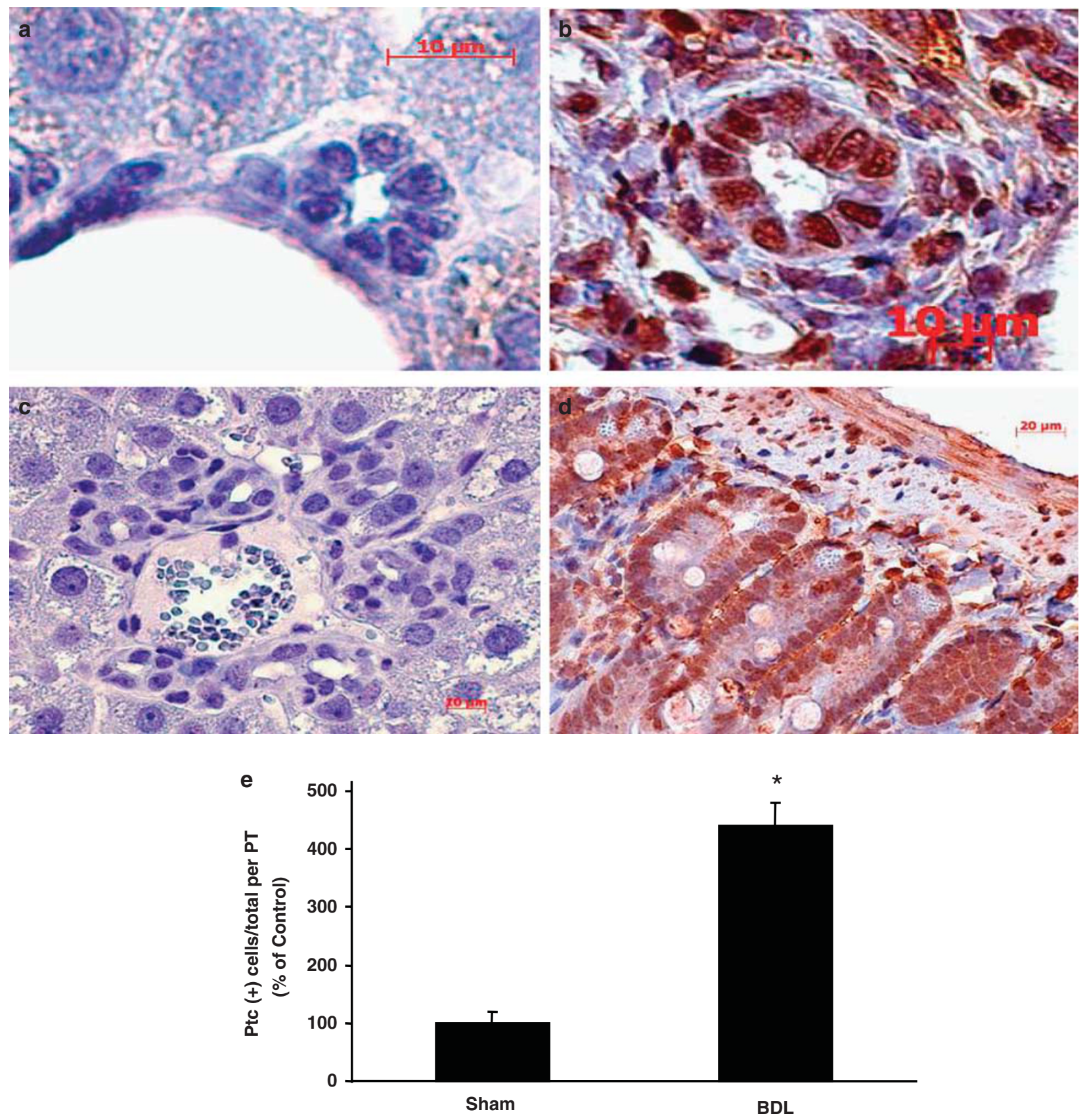

Figure 4 Ptc immunohistochemistry. Liver sections from representative mice at 1 week postsurgery (a) sham-operated control, (b) BDL mouse, (c) negative control, that is, section from BDL mouse processed without primary anti-Ptc antibody, (d) positive control, that is, intestine from control mouse demonstrating expected Ptc $(+)$ brown cells. (e) Ptc $(+)$ and Ptc(-) cells were counted in all PT in seven randomly-selected fields/section in three mice that were randomly selected from each group. Results are expressed as mean \pm s.e.m. Ptc( + ) cells/total cells per PT. ${ }^{*} P<0.05$ vs sham-operated control. $(\mathbf{a}, \mathbf{b})$ Original magnification $\times 100$. (c) Magnification $\times 100$. (d) Magnification $\times 630$. 


\section{Cholangiocyte 603B and HSC-8B Lines Basally Express Hedgehog Components}

To begin to clarify the role of the Hh pathway in liver epithelial repair, we studied cultures of cholangiocytes and myofibroblastic HSCs. The cholangiocyte line was derived from healthy adult mouse liver, ${ }^{28,29}$ whereas the HSC line was generated from a single HSC clone that had been isolated from an adult rat with CCl4-induced cirrhosis. ${ }^{26}$ These cell lines have been extensively utilized by other groups to study cholangiocyte biology $y^{29,37}$ and extracellular matrix production, respectively. ${ }^{26,27}$ Our quantitative real-time PCR (QPCR) analysis demonstrated that both cell types expressed $\mathrm{Hh}$ ligands, the $\mathrm{Hh}$ receptor (Ptc) and co-receptor (Smo), and several Hh-responsive target genes (eg, Gli1, 2, and 3).
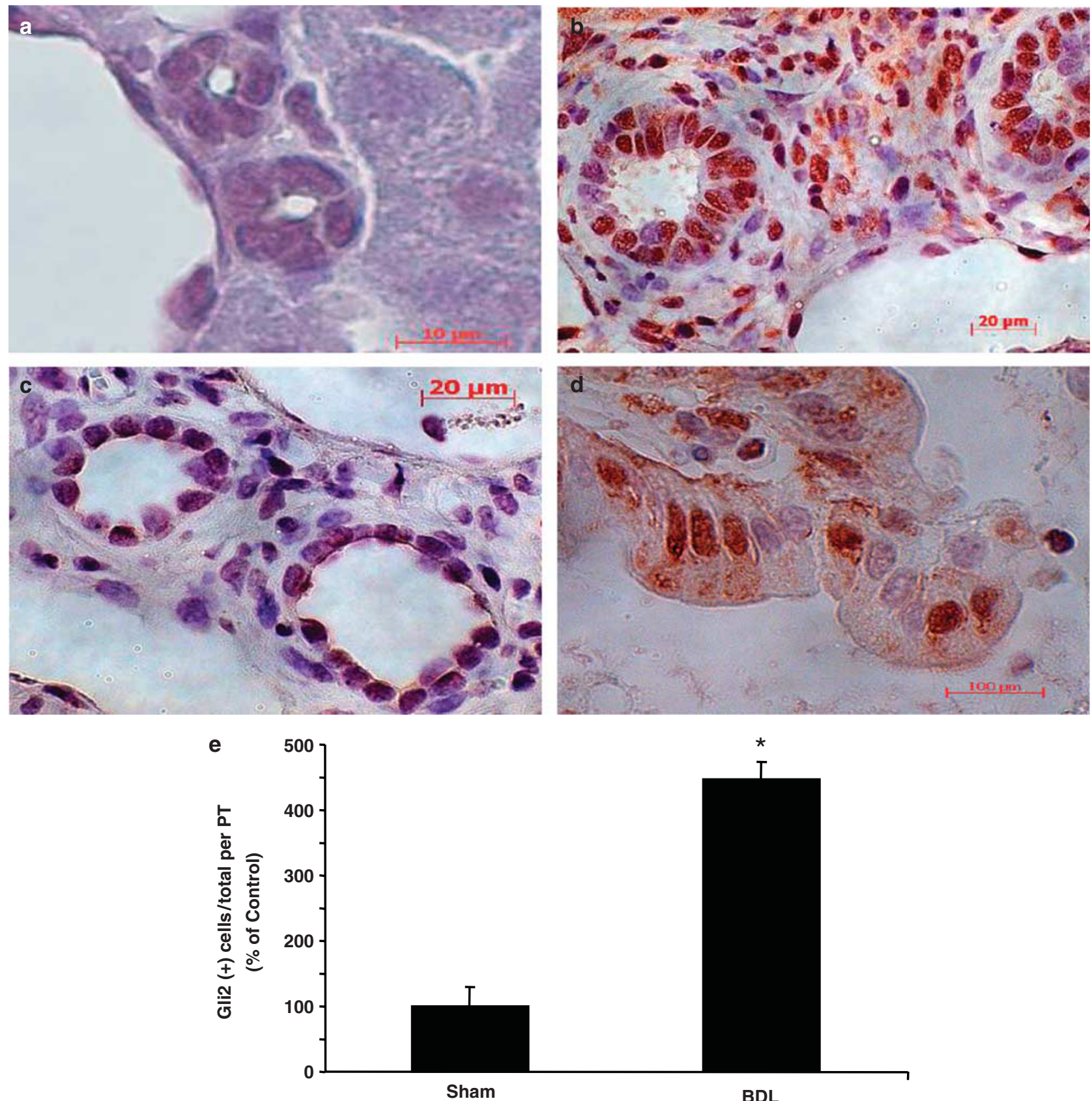

Figure 5 Gli-2 immunohistochemistry. Liver sections from representative mice at 1 week postsurgery (a) sham-operated control, (b) BDL mouse, (c) negative control, that is, section from BDL mouse processed without primary anti-Gli2 antibody (diffuse, faint brown cytoplasmic staining is considered to be nonspecific), (d) positive control, that is, intestine from control mouse demonstrating expected deeply-brown Gli2(+) cells. (e) Gli2( + ) and Gli2(-) cells were counted in all portal tracts (PTs) in seven randomly selected fields/section in three mice that were randomly selected from each group. Results are expressed as mean \pm s.e.m. Gli2 $(+)$ cells/total cells per PT. ${ }^{*} P<0.05$ vs sham-operated control. (a) Original magnification $\times 100$. (b) Original magnification $\times 630$. 
All of these Hh pathway components were easily detected within 21-28 QPCR amplification cycles, and readily demonstrated on agarose gels of QRT-PCR products from the respective cell types (Figure 6a). Interestingly, although monocultures of cholangiocytes expressed Ihh, expression of Shh could not be detected under these conditions. Con- versely, HSC monocultures expressed both Shh and Ihh mRNA. Pertinent to our findings in BDL livers, treating HSC with epidermal growth factor (EGF) further increased their expression of Hh ligands (Figure 6b).

As $\mathrm{Hh}$ activity has not been documented previously in mature cholangiocytes, but Hh signaling is known to occur in a

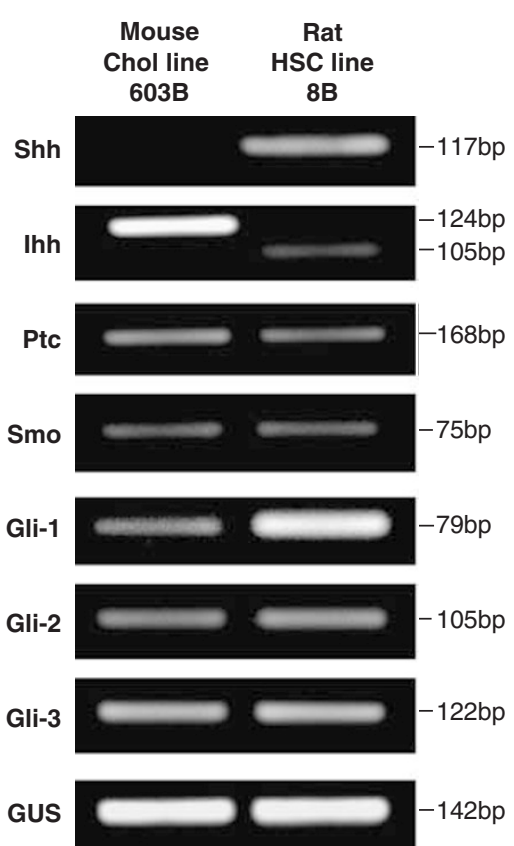

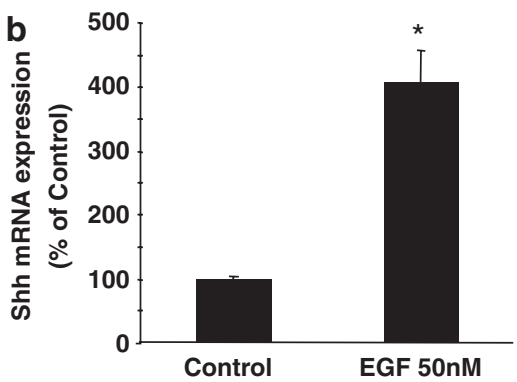

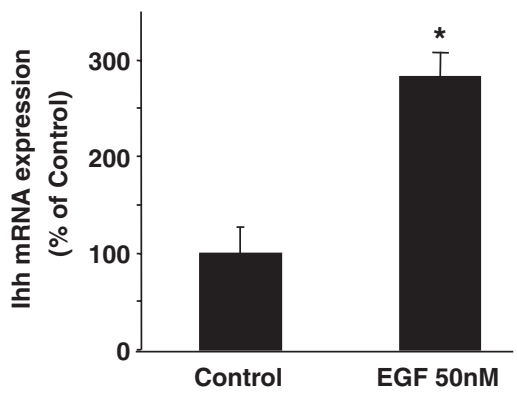

C

CK19

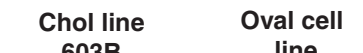

line

Hepatocytes

Brain tissue

Negative

Contro

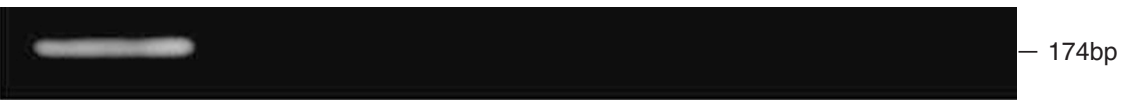

AQP-1

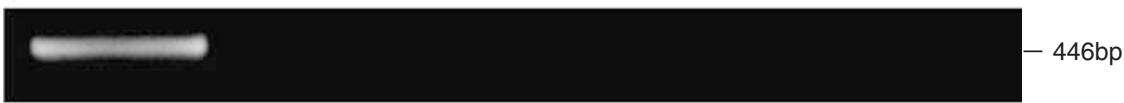

NCAM

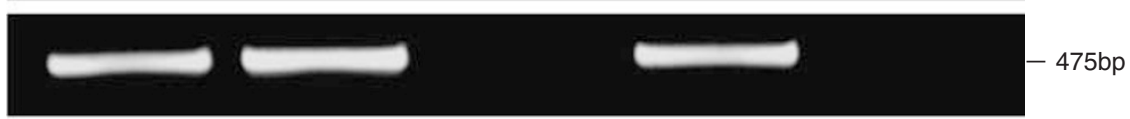

MpK

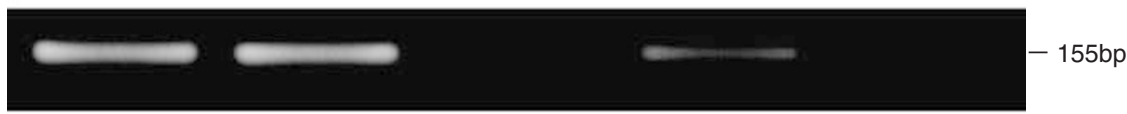

cKit

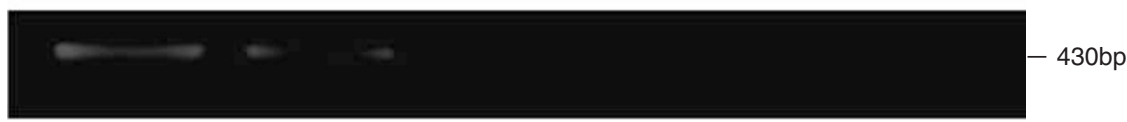

Albumin

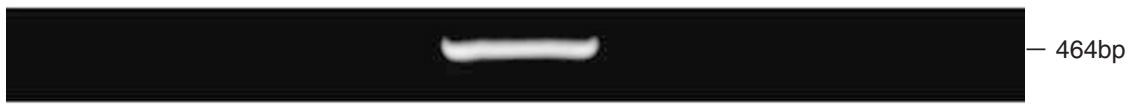

GUS

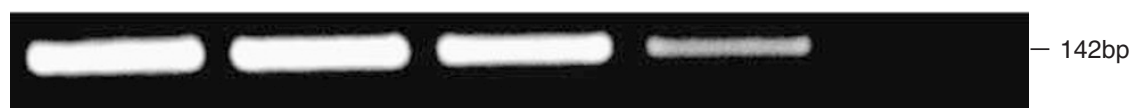

Figure 6 Hh pathway in cholangiocyte and hepatic stellate cell (HSC) monocultures. 2\% agarose gel of QRT-PCR amplicons showing expression of Hh ligands, receptors and postreceptor signalling components (a). HSC 8B were treated with $50 \mathrm{nM}$ EGF for $16 \mathrm{~h}$, and then Shh and Ihh mRNA expressions were evaluated by real-time RT-PCR. Glucuronidase (Gus) was used to evaluate mRNA loading. Mean \pm s.e.m. of triplicate experiments, ${ }^{*} P<0.05$ for EGF-treated $v s$ control (b). $2 \%$ agarose gel of RT-PCR amplicons comparing expression of various differentiation markers and the housekeeping gene, Gus, in mouse Chol $603 \mathrm{~B}$, mouse oval cells, mouse brain tissue, and mouse hepatocytes (c). 
many types of progenitor cells ${ }^{12-14}$ and was noted in some cholangiocarcinoma cell lines, ${ }^{38}$ we used RT-PCR to screen various differentiation markers in our cholangiocyte line (Figure 6c). Controls for these analyses included putative hepatic epithelial progenitors (ie, murine oval cells), ${ }^{30,39}$ mature primary mouse hepatocytes, and mouse brain tissue (a source of neural markers). As expected, although albumin transcripts were readily apparent in hepatocytes, transcripts for markers of mature and immature bile duct cells could not be detected in these cells. In contrast, the cholangiocytes expressed some markers of mature bile duct cells, such as aquaporin (AQP)-1 ${ }^{40}$ and cytokeratin (CK)-19, ${ }^{41,42}$ but not albumin. Notably, however, under our culture conditions, these cholangiocytes also expressed several markers of immature bile ductular cells, including neural markers (eg, NCAM),${ }^{43}$ muscle pyruvate kinase (mpk), ${ }^{44}$ and c-kit. ${ }^{45}$ The latter transcripts were also demonstrated in oval cells, which are known to coexpress neural, smooth muscle and progenitor markers. ${ }^{44-47}$ These data suggest that Hh pathway activity occurs in immature cholangiocytes (ie, bile ductular cells).

\section{Coculture Promotes Both Cholangiocyte and HSC Growth}

To assess potential paracrine signaling between HSC and immature cholangiocytes, the cells were placed in transwell cocultures. Cell proliferation (BrdU incorporation), apoptosis (caspase 3/7 activity), and net growth (cell number) of the cocultured cholangiocytes and HSC were compared to that of monocultures of the respective cells. For both cell types, coculture increased proliferation (Figure $7 \mathrm{c}$ and $\mathrm{d}$ ), decreased apoptosis (Figure 7e and f), and improved overall growth (Figure $7 \mathrm{a}$ and $\mathrm{b}$ ), although greater effects were noted for cholangiocytes (Figure 7a, c and e) than HSC (Figure 7b, d and $\mathrm{f}$ ).

\section{Coculturing Cholangiocytes and HSC Alters Hedgehog Pathway}

Coculture also influenced $\mathrm{Hh}$ signaling in both cell types. During coculture HSC production of Hh ligand mRNAs increased significantly (Figure 8b): Shh transcripts increased 1.6-fold within 3 days and remained at this level throughout the entire 6-day study period; levels of Ihh mRNA doubled by 6 days coculture. In contrast to what we observed in BDL mice, cholangiocyte expression of Ihh mRNA declined significantly during coculture with HSC (Figure 8a). The mechanisms for this response were not investigated, but might include negative regulation of Ihh gene expression by accumulation of Ihh protein that was produced by cholangiocytes and/or HSC in the cocultures. In any case, the differential changes in Hh ligand expression were accompanied by strong upregulation of Hh signaling in cholangiocytes. For example, cholangiocyte expression of the Hh-target genes, Gli-1 and -2, increased significantly during coculture (Figure $8 \mathrm{c}$ and e). Gli-2 mRNA levels almost
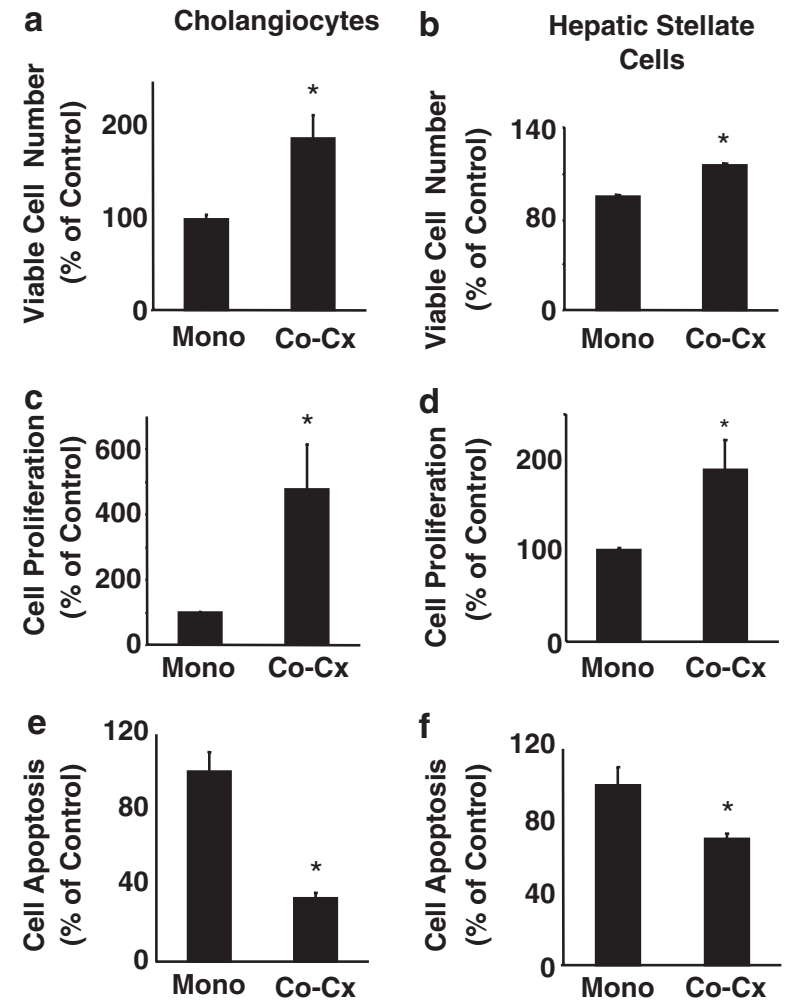

Figure 7 Effects of coculture on Cholangiocyte and HSC viability, proliferation, and apoptosis. Cholangiocytes $(\mathbf{a}, \mathbf{c}, \mathbf{e})$ and HSC $(\mathbf{b}, \mathbf{d}, \mathbf{f})$ were cultured alone (Mono) or in coculture systems (Co-Cx); viability (a, b), BrdU incorporation (c, d), and caspase $3 / 7$ activity $(\mathbf{e}, \mathbf{f})$ were evaluated in both cell types. Mean \pm s.e.m. data from three experiments. $\left({ }^{*} P<0.05\right.$ vs monoculture).

doubled within three days and then declined as Gli-1 mRNA levels rose to sevenfold greater than parallel cholangiocyte monocultures by day six of coculture. Induction of Hh target genes was much less dramatic in HSC, which express high basal Hh activity, ${ }^{32}$ although transient increases in both Gli-1 and -2 transcripts did occur early during coculture (Figure $8 \mathrm{~d}$ and $\mathrm{f}$ ).

\section{Neutralization of HSC-Derived Hh Ligands Inhibits Coculture Effects on Cell Growth}

Our earlier work showed that autocrine production of $\mathrm{Hh}$ ligands promotes the growth and viability of myofibroblastic stellate cells. ${ }^{32}$ Therefore, here we sought to determine to what extent, if any, exposure to HSC-derived Hh ligands contributed to the beneficial effects of coculture on cholangiocyte growth. Conditioned medium was obtained, and treated with either nonspecific IgG or an equivalent amount of neutralizing antibody to Shh/Ihh. Following these treatments, the respective HSC-conditioned mediums were added to cholangiocyte monocultures; cholangiocyte proliferation and apoptotic activity were compared 3 days later. Compared to control IgG treatment, neutralizing Hh ligands in the HSC conditioned medium decreased cholangiocyte proliferation 

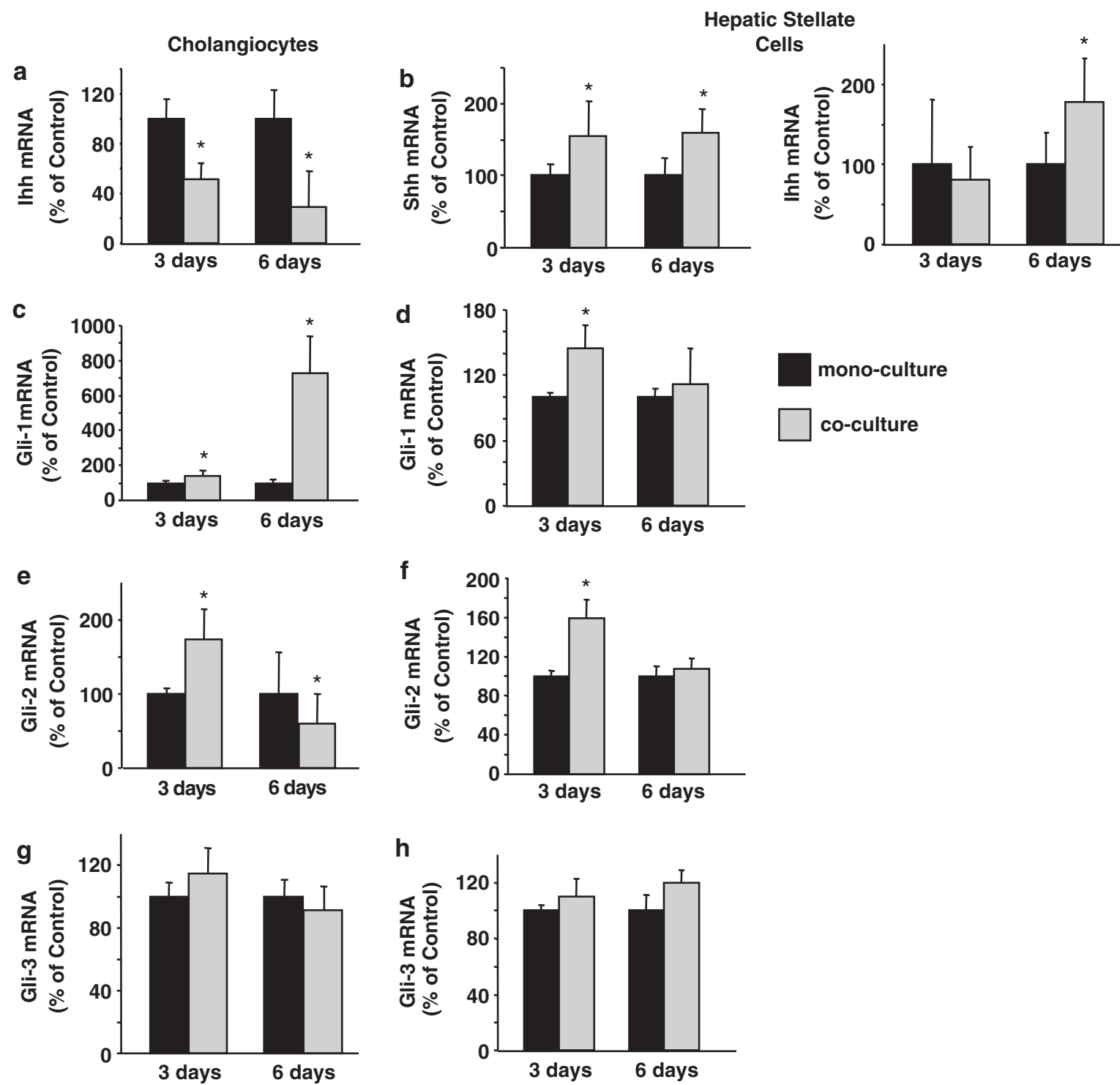

Figure 8 Effects of coculture on Hh Pathway. Cholangiocytes $(\mathbf{a}, \mathbf{c}, \mathbf{e}, \mathbf{g})$ and HSC (b, d, $\mathbf{f}, \mathbf{h})$ were cocultured for 3 and 6 days. Q-RT PCR analysis was performed to compare Hh components mRNA expression in control monocultures (black bars) and in cocultured cells (gray bars). Mean \pm s.e.m. data from three experiments. ${ }^{*} P<0.05$ vs monoculture).

by $\sim 50 \%$ (Figure $9 \mathrm{a}$ ), and doubled cholangiocyte apoptotic activity (Figure 9b), demonstrating that paracrine $\mathrm{Hh}$ mediated signaling between cholangiocytes and HSC promotes cholangiocyte growth. A similar approach was then used to assess the impact of cholangiocyte-derived $\mathrm{Hh}$ ligands on HSC growth. Nonspecific IgG did not block the beneficial effects of cholangiocyte-conditioned medium on HSC growth (Figure 9c and d). However, adding Hh-neutralizing antibodies to cholangiocyte-conditioned medium significantly reduced proliferation (Figure 9c) and increased apoptosis (Figure 9d) of myofibroblastic HSC. These findings support the possibility that cholangiocyte-derived Hh ligands provided paracrine signals that enhanced the growth of myofibroblastic HSC.

\section{Aberrant Responses to BDL in Patched-Deficient Mice}

To assess more directly the role of the Hh pathway in the hepatic response to BDL, BDL experiments were repeated using PtcLacZ mice and their wild-type (WT) littermates. PtcLacZ mice have a heterozygous deficiency of Ptc because the coding sequence on one Ptc allele is replaced with LacZ. ${ }^{23}$ The livers of PtcLacZ mice (Figure 11b) appeared similar to WT mice (Figure 11a) after sham surgery. BDL also seemed to produce similar levels of initial liver injury in WT and PtcLacZ mice. At one week after BDL, for example, serum alanine aminotransferase (ALT) levels (WT: $1475 \pm 495$ vs PtcLacZ: $1284 \pm 159$ IU/L, $P=$ NS) and the numbers of necrotic foci on H\&E-stained liver sections (data not shown) were not different in the two groups. On the other hand, the initial 
a

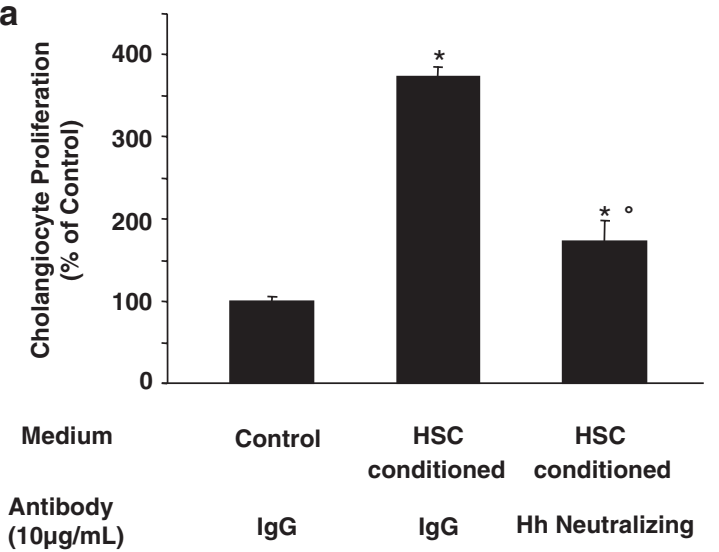

C

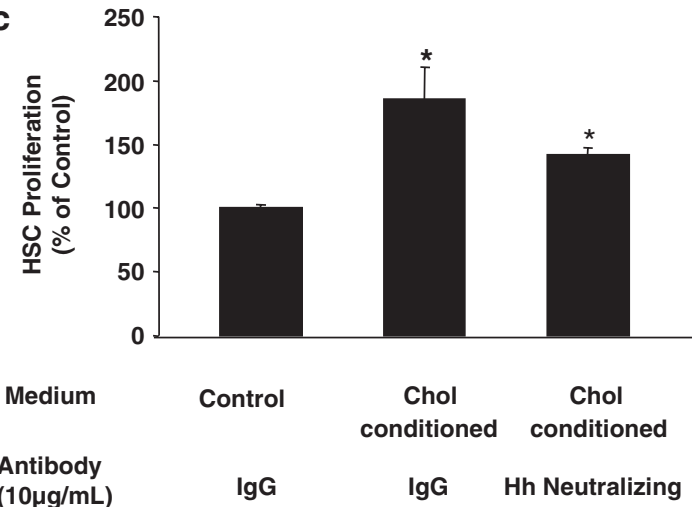

b

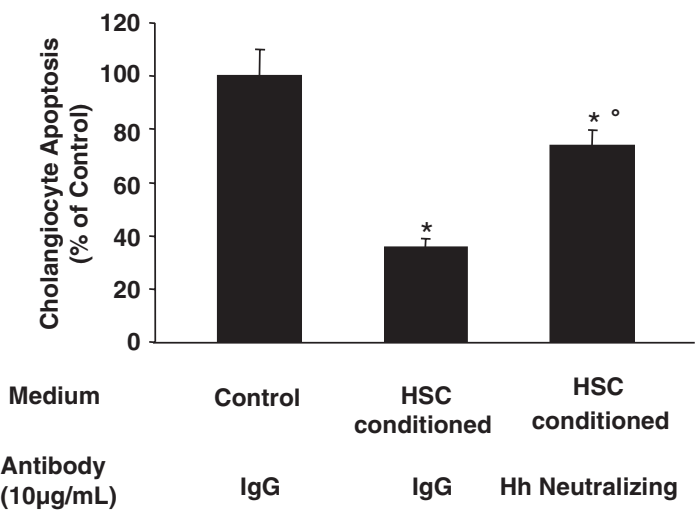

d

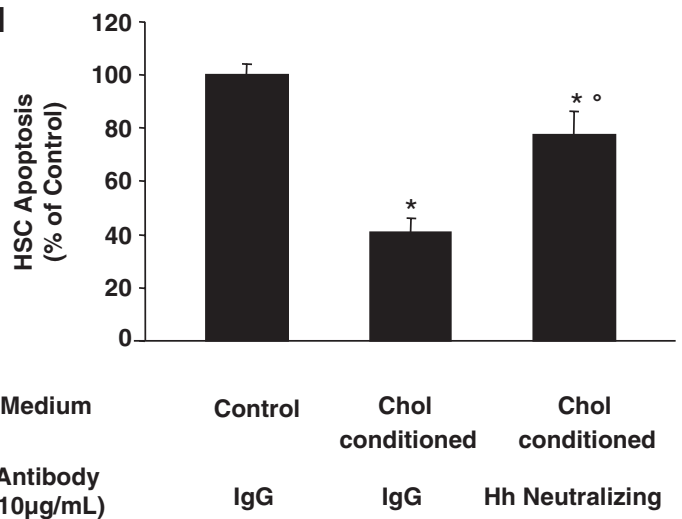

Figure 9 Effect of neutralizing HSC-derived Hh ligands on cholangiocyte growth rate. Cholangiocytes and HSC were cultured for 3 days; conditioned medium was collected and transferred into 96-well/plate monoculture systems for each cell type, after adding Hh neutralizing antibody (5E1 $10 \mu \mathrm{g} / \mathrm{ml})$ or IgG1 isotype control antibody. BrdU incorporation (a) and caspase 3/7 activity (b) in cholangiocytes or HSC (c) d) were then evaluated after 3 days of culture, normalized to naïve monoculture and compared. Mean \pm s.e.m. from triplicate experiments. $\left({ }^{*} P<0.05 \%\right.$ vs ctrl $\operatorname{lgG} ;{ }^{\circ} P<0.05 \%$ vs conditioned medium with $\lg G)$.

fibroproliferative response to BDL differed significantly in PtcLacZ and WT mice. At 1 week post-BDL (Figure 10), hepatic expression of $\alpha$-sma mRNA, a marker of myofibroblastic cells, was twofold higher in the PtcLacZ group than WT controls (Figure 10a). PtcLacZ mice also expressed significantly higher levels of collagen $1 \alpha(\mathrm{I})$ (Figure 10b) and fibronectin (Figure 10c).

By 2 weeks post-BDL, expression of these fibrosis-related genes was similar in WT and PtcLacZ mice (data not shown). However, at this time point, the PtcLacZ mice exhibited numerous large areas of necrotic-appearing parenchyma (Figure 11d and e), whereas this was almost never noted in BDL-WT mice (Figure 11c and e). Also, the portal tracts of BDL-PtcLacZ mice were generally larger (Figure $11 \mathrm{~h}$ ) and contained more poorly-organized ductular structures than BDL-WT mice (Figure 11f and g). The latter are better visualized on sections incubated with antibodies to pancytokeratin to reveal bile ductular cells (Figure 11i and j). Taken together, these findings demonstrate an altered response to $\mathrm{BDL}$ in mice that are heterozygously deficient for the $\mathrm{Hh}$ receptor, Ptc.

\section{DISCUSSION}

These studies provide novel evidence that Hh signaling plays a role in the hepatic response to biliary obstruction. Two of the major cell types that accumulate during cholestatic liver damage, myofibroblastic cells and immature cholangiocytes (ie, bile ductular cells), ${ }^{1}$ express the Hh receptor, Ptc. Ptcexpressing cells are targets for extracellular Hh ligands, such as Shh and Ihh. Interaction of Hh ligands with Ptc releases the Ptc coreceptor, Smoothened (Smo), from the inhibitory influence of Ptc. This permits intracellular propagation of Hh-initiated signals and leads to activation of Hh-regulated trans-activating factors, including the Gli family of transcription factors. Gli binding, in turn, regulates the expression of Hh target genes, which include Ptc and Gli family members themselves. ${ }^{13}$ Both myofibroblastic HSC and immature cholangiocytes express these $\mathrm{Hh}$ target genes and thus, are capable of $\mathrm{Hh}$ transcriptional activity.

Activation of Hh signaling generally enhances the viability of $\operatorname{Ptc}(+) v e$ cells, providing them a selective growth advantage over neighboring cells that lack $\mathrm{Hh}$ receptors. This promotes the transient amplification of Hh-responsive 

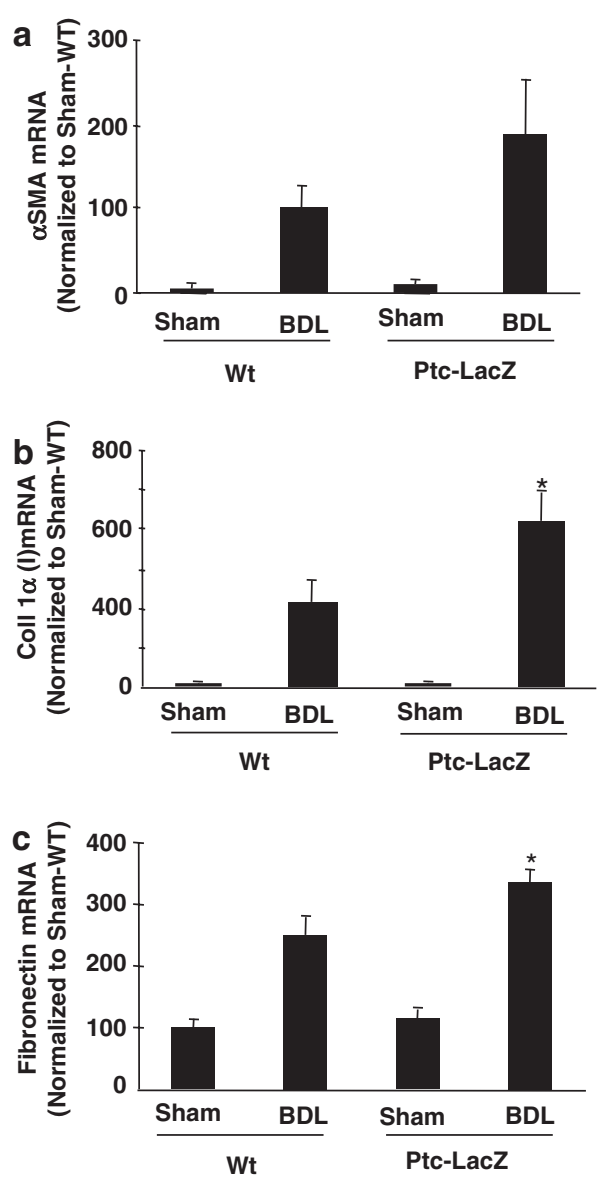

Figure 10 Markers of liver fibrosis in PtcLacZ and WT mice. Total RNA was isolated from WT and PtcLacZ mice 1 week after sham surgery or BDL $(n=6$ mice/group) and analyzed by QRT-PCR. All results are normalized to shamoperated WT controls. (a) $\alpha$-SMA, (b) collagen $1 \alpha$ (I), (c) fibronectin. ${ }^{*} P<0.05$ vs WT BDL.

cell populations whose ultimate fate is dictated by the local availability of various mitogens and differentiating factors. ${ }^{48,49}$ Following BDL, net hepatic expression of $\mathrm{Hh}$ ligands and $\mathrm{Hh}$ target genes increases significantly as myofibroblastic HSC and bile ductular cells accumulate. Immunohistochemistry demonstrates that Hh ligands, receptor and transcriptional targets localize in bile ductular cells and stromal cells that accumulate in portal areas after BDL. Coculture of myofibroblastic HSC with immature cholangiocytes also upregulates Hh ligand expression, induces expression of Hh-target genes, and promotes the viability and growth of both cell types. Addition of neutralizing antibodies to Hh ligands reverses these trophic effects in vitro, suggesting that $\mathrm{Hh}$ signaling might modulate the fibroproliferative response to BDL. Additional support for the latter concept is provided by studies of PtcLacZ mice, which have an impaired ability to constrain Hh signaling due to heterozygous deficiency of Ptc. ${ }^{23,50-52}$ Following BDL, such mice exhibit premature induction of various fibrosis genes and subsequently manifest a particularly intense ductular reaction and more expanded, fibrotic portal areas than wildtype mice.

The possibility that Hh signaling might orchestrate injury responses in adult livers was somewhat unanticipated given present understanding of the $\mathrm{Hh}$ pathway. This signaling system is highly conserved across species, and regulates multiple, seemingly disparate, aspects of embryogenesis, including development of the nervous system, ${ }^{22}$ heart, ${ }^{19}$ thyroid, ${ }^{20}$ lung, ${ }^{16,53}$ proximal gastrointestinal tract, ${ }^{17,18,21}$ and skeleton. ${ }^{15}$ Although one study involving embryo explants suggested that Hh activity may also be required for ultimate hepatic specification of primitive cells in the ventral endoderm, ${ }^{11}$ the lack of an obvious hepatic phenotype in mice with targeted disruption of various Hh pathway components has cast doubt about the importance of Hh signaling for fetal liver development. ${ }^{54}$ Similarly, because Hh pathway activity has not been demonstrated in mature hepatocytes or cholangiocytes of healthy adult livers, there has been little interest in exploring its role in adult liver regeneration.

However, the latter issue merits reconsideration in light of the present data, which complement and extend other evidence for Hh pathway activation during various liver diseases. For example, Shakel et $a l^{55}$ reported that Ptc was the fourth most upregulated gene in their microarray analysis of liver samples from patients with primary biliary cirrhosis (PBC). PBC is characterized by progressive loss of mature intralobular bile ducts, neocholangiolar (ie, bile ductular cell) proliferation and fibrosis. ${ }^{1,256} \mathrm{Hh}$ transcriptional activity has also been demonstrated in some cholangiocarcinoma cell lines. $^{38}$ Recently, we ${ }^{57}$ and two other groups ${ }^{58,59}$ reported evidence for increased $\mathrm{Hh}$ activity in hepatoblastoma cell lines and a subset of human hepatocellular carcinomas. Hence, Hh activity appears to increase in adult livers that are enriched with relatively immature liver epithelial cells. This is intriguing because the present studies and our earlier work demonstrate that activated HSC provide a source of $\mathrm{Hh}$ ligands, ${ }^{32}$ and liver progenitors are known to increase in parallel with myofibroblastic HSC as cirrhosis evolves during chronic liver damage. ${ }^{60}$

Differential sensitivity to Hh signaling during fetal and adult tissue growth is not unprecedented. Indeed, in several other tissues that are not known to be major developmental Hh targets (eg, breast, prostate, and colon), ${ }^{36,61,62}$ the $\mathrm{Hh}$ pathway regulates tissue remodeling in response to demands imposed by metabolic and/or inflammatory stresses during adult life. ${ }^{63}$ During chronic cholestatic liver injury induced by BDL, myofibroblastic HSC join portal fibroblasts that accumulate in the fibrous stroma near proliferating bile ductular cells. Expansion of myofibroblastic cell populations is known to result, at least in part, from bile ductular cell release of cytokines, such as PDGF-BB. ${ }^{4,6}$ It is thought that the myofibroblastic cells, in turn, modulate the proliferative activity of themselves and neighboring bile ductular cells. ${ }^{64-66}$ Our findings suggest additional factors that contribute to these phenomena. Namely, the myofibroblastic HSC produce 

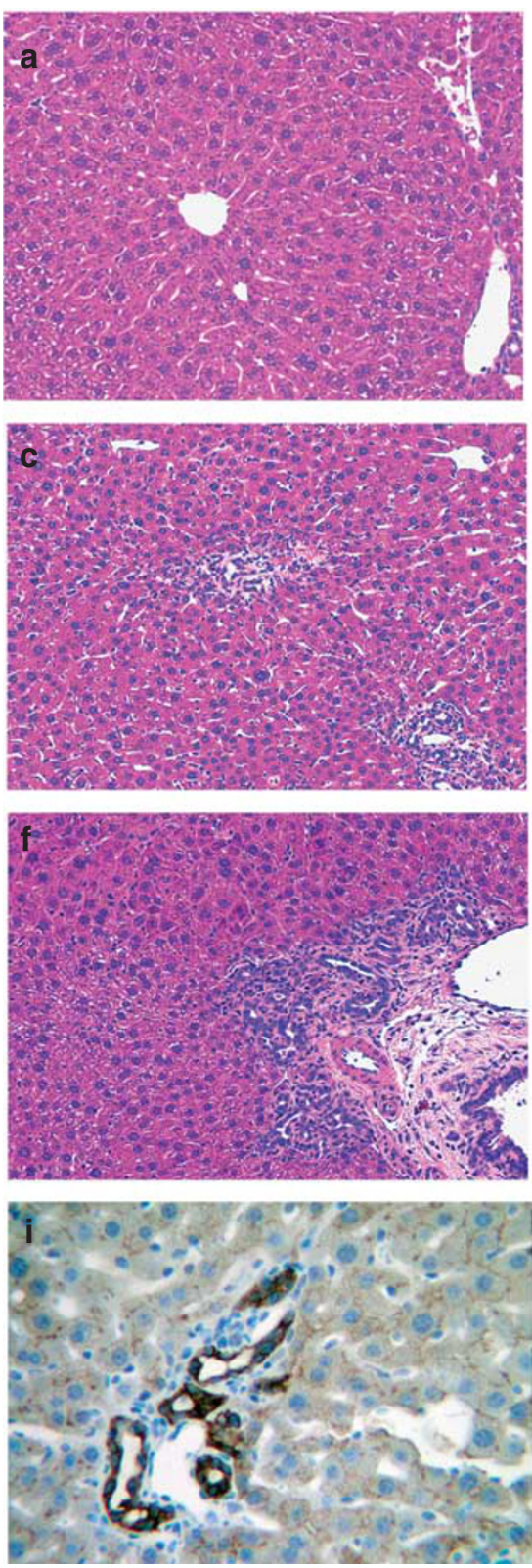
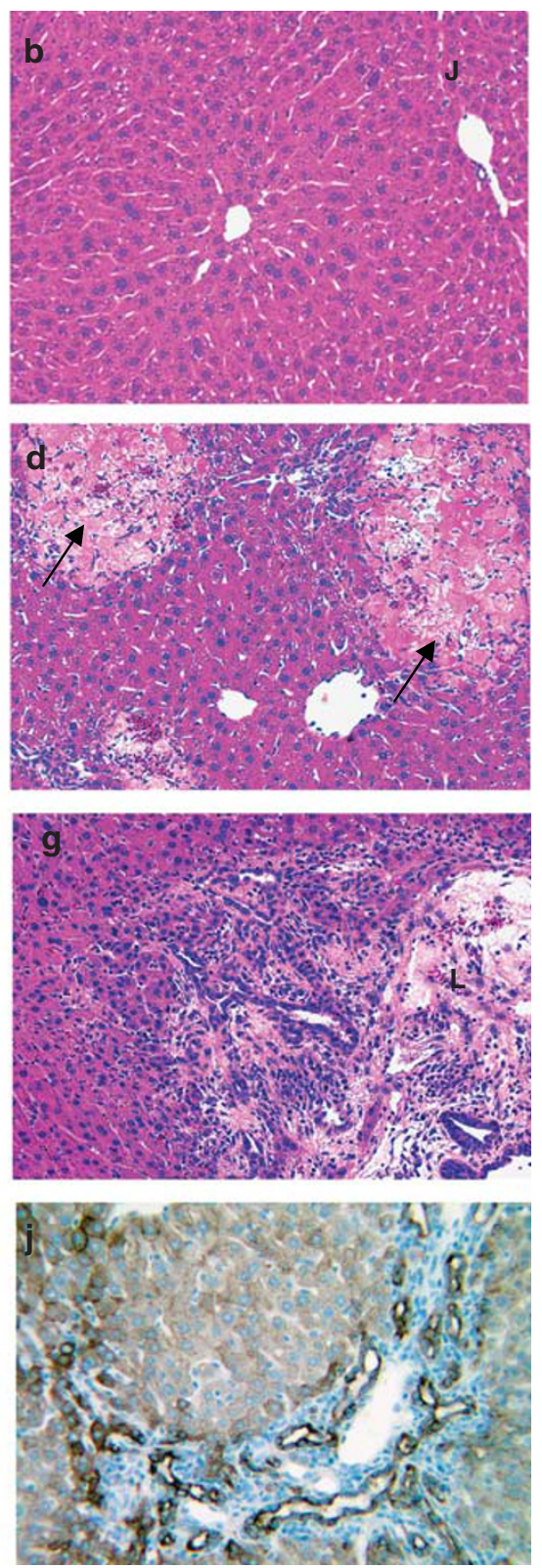
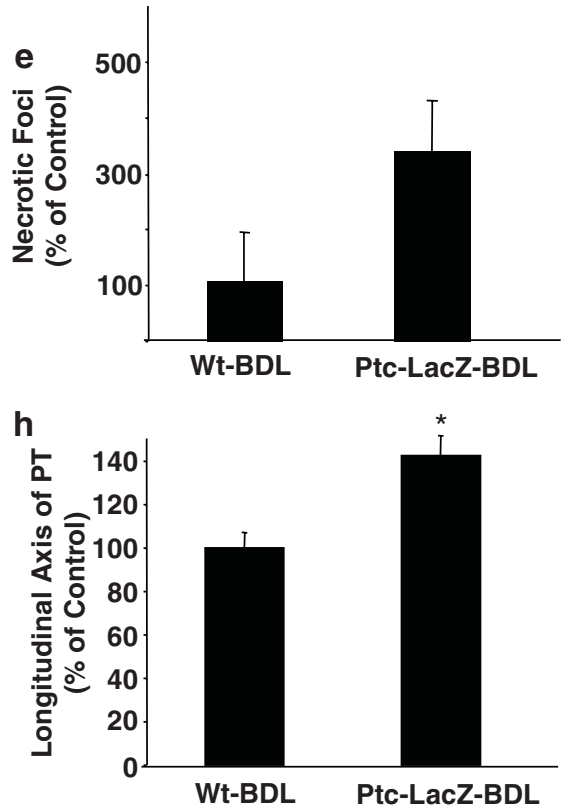

Figure 11 Altered response to BDL in PtcLacZ mice. (a-g) H\&E staining of liver sections from representative mice ( $\times 200)$. Sham-operated WT mouse (a) and PtcLacZ mouse (b). At 2 post-BDL WT mouse (c) and PtcLacZ mouse (d). Arrows mark necrotic foci. These were quantified by reviewing 10 different $\times 100$ fields per section in all mice ( $n=6$ mice/group). Results (mean \pm s.e.m.) are expressed as percentage of necrotic foci in WT controls after BDL (e). Portal tract 2 weeks post-BDL in WT mouse (f) and PtcLacZ mouse (g). Portal tract size was evaluated by morphometric analysis of sections from all mice ( $n=6$ mice/group). Results in PtcLacZ-BDL mice are expressed relative to WT-BDL controls. ${ }^{\star} P<0.05$ vs WT-BDL (h). Pancytokeratin staining of liver sections from representative WT mouse (i) and PtcLacZ mouse (j) at $\times 400$ of magnification.

Hh ligands that provide trophic signals for bile ductular cells. Moreover, the ductular cells perpetuate this relationship by producing $\mathrm{Hh}$ ligands that promote the viability of their myofibroblastic neighbors. ${ }^{32}$

More research is needed to determine if such crosstalk influences other aspects of HSC or cholangiocyte fate, such as the state of cellular differentiation. Such work is likely to be difficult, however, because the origin of both cell types is uncertain. Coexpression of epithelial, mesenchymal, and/or neural markers has been reported in HSC, ${ }^{12,67-71}$ making it difficult to discern their derivation and giving rise to speculation that such cells may undergo mesenchymal-epithelial transitions. ${ }^{69,71}$ Gene expression profiles of HSC and other liver fibroblastic cells also change significantly during liver injury, ${ }^{70}$ further confounding assessment of cell lineage. The portal fibroblast marker ecto-nucleotidase NTPDase 2, for example, is down-regulated in $\alpha-\operatorname{SMA}(+)$ portal fibroblasts during biliary cirrhosis, while $\alpha-\operatorname{SMA}(+)$ cells in centri- 
lobular areas (presumably myofibroblastic HSC) begin to express this marker in non-biliary cirrhosis. ${ }^{72}$ The derivation of ductular cells is also controversial: de-differentiating mature hepatocytes and/or bile duct cells, as well as differentiating bipotential hepatoblasts (ie, oval cells) have all been proposed as potential sources. ${ }^{73-75}$ Immunohistochemistry of BDL livers demonstrated that some bile ductular cells expressed Ptc and Gli-2, suggesting that relatively immature liver epithelial cells are $\mathrm{Hh}$ targets. Our in vitro studies support this concept because, under our culture conditions, the Ptc- $(+)$ ve cholangiocyte line coexpressed several oval cell markers, mpk and c-kit, ${ }^{44-47}$ and the immature cholangiocyte marker, N-CAM, ${ }^{3,43,76,77}$ as well as markers of more mature cholangiocytes (ie, aquaporin-1 and CK-19). If further research verifies that $\mathrm{Hh}$ signaling promotes the outgrowth of relatively immature liver epithelial cells, this might explain why patchy lobular necrosis was worse in PtcLacZ mice than WT mice after BDL. Namely, reconstitution of a functional biliary system was more impaired in PtcLacZ livers which maintained a microenvironment that was more conducive to the growth of less mature epithelial cells. In addition, by enhancing the survival of myofibroblastic HSC, Hh activity might enhance accumulation of transforming growth factor- $\beta$, or other activated HSC products that reduce hepatocyte viability and proliferation. ${ }^{64}$

As is evident from this discussion, the present work opens a new field of liver research with broad basic and clinical implications. The possibility that adult livers resurrect developmental signaling systems, such as the Hh pathway, to guide remodeling of the biliary epithelia and stroma after cholestatic injury suggests novel diagnostic and therapeutic targets in various cholangiopathies.

\section{ACKNOWLEDGEMENT}

We thank Dr M Rojkind for the kind gift of rat hepatic stellate line; Dr GJ Gores and Yoshiyuki Ueno for the kind gift of murine cholangiocyte cell line; Dr BE Petersen for the kind gift of murine hepatic progenitor cell line (OV). The 5E1 antibody was obtained from the Developmental Studies Hybridoma Bank developed under Department of Biological Sciences, lowa City, IA 52242, USA. This work was supported by National Institutes of Health Grants RO1-DK053792 (to Anna Mae Diehl) and RO1-AA010154 (to Anna Mae Diehl).

1. Lazaridis KN, Strazzabosco M, Larusso NF. The cholangiopathies: disorders of biliary epithelia. Gastroenterology 2004;127:1565-1577.

2. Desmet V, Roskams T, Van Eyken P. Ductular reaction in the liver. Pathol Res Pract 1995;191:513-524.

3. Roskams T, van den Oord JJ, De Vos R, et al. Neuroendocrine features of reactive bile ductules in cholestatic liver disease. Am J Pathol 1990;137:1019-1025.

4. Tuchweber B, Desmouliere A, Bochaton-Piallat ML, et al. Proliferation and phenotypic modulation of portal fibroblasts in the early stages of cholestatic fibrosis in the rat. Lab Invest 1996:74:265-278.

5. Kinnman N, Goria O, Wendum D, et al. Hepatic stellate cell proliferation is an early platelet-derived growth factor-mediated cellular event in rat cholestatic liver injury. Lab Invest 2001;81:1709-1716.

6. Kinnman N, Hultcrantz $R$, Barbu $V$, et al. PDGF-mediated chemoattraction of hepatic stellate cells by bile duct segments in cholestatic liver injury. Lab Invest 2000;80:697-707.

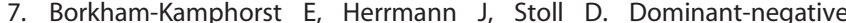
soluble PDGF-beta receptor inhibits hepatic stellate cell activation and attenuates liver fibrosis. Lab Invest 2004;84:766-777.

8. Grappone C, Pinzani M, Parola M, et al. Expression of platelet-derived growth factor in newly formed cholangiocytes during experimental biliary fibrosis in rats. J Hepatol 1999;31:100-109.

9. Kinnman N, Francoz C, Barbu V, et al. The myofibroblastic conversion of peribiliary fibrogenic cells distinct from hepatic stellate cells is stimulated by platelet-derived growth factor during liver fibrogenesis. Lab Invest 2003;83:163-173.

10. Milani S, Herbst $H$, Schuppan $D$, et al. Procollagen expression by nonparenchymal rat liver cells in experimental biliary fibrosis. Gastroenterology 1990;98:175-184.

11. Deutsch G, Jung J, Zheng $M$, et al. A bipotential precursor population for pancreas and liver within the embryonic endoderm. Development 2001;128:871-881.

12. Sicklick JK, Li YX, Melhem A, et al. Hedgehog signaling maintains resident hepatic progenitors throughout life. Am J Physiol Gastrointest Liver Physiol 2006;290:G859-G870.

13. Taipale J, Beachy PA. The Hedgehog and Wnt signalling pathways in cancer. Nature 2001;411:349-354.

14. Watkins DN, Berman DM, Burkholder SG, et al. Hedgehog signalling within airway epithelial progenitors and in small-cell lung cancer. Nature 2003;422:313-317.

15. Brand-Saberi B. Genetic and epigenetic control of skeletal muscle development. Ann Anat 2005:187:199-207.

16. Cardoso WV, Lu J. Regulation of early lung morphogenesis: questions, facts and controversies. Development 2006;133:1611-1624.

17. Jaskoll $\mathrm{T}$, Leo $\mathrm{T}$, Witcher $\mathrm{D}$, et al. Sonic hedgehog signaling plays an essential role during embryonic salivary gland epithelial branching morphogenesis. Dev Dyn 2004;229:722-732.

18. Kawahira H, Ma NH, Tzanakakis ES, et al. Combined activities of hedgehog signaling inhibitors regulate pancreas development. Development 2003;130:4871-4879.

19. Lavine $\mathrm{KJ}, \mathrm{Yu} \mathrm{K}$, White $\mathrm{AC}$, et al. Endocardial and epicardial derived FGF signals regulate myocardial proliferation and differentiation in vivo. Dev Cell 2005;8:85-95.

20. Shah DK, Hager-Theodorides AL, Outram SV, et al. Reduced thymocyte development in sonic hedgehog knockout embryos. J Immunol 2004;172:2296-2306.

21. Spencer-Dene B, Sala FG, Bellusci S, et al. Stomach development is dependent on fibroblast growth factor 10/fibroblast growth factor receptor 2b-mediated signaling. Gastroenterology 2006;130:12331244.

22. Wilson L, Maden M. The mechanisms of dorsoventral patterning in the vertebrate neural tube. Dev Biol 2005;282:1-13.

23. Goodrich LV, Milenkovic L, Higgins KM, et al. Altered neural cell fates and medulloblastoma in mouse patched mutants. Science 1997;277:1109-1113.

24. Yang L, Chan CC, Kwon OS, et al. Regulation of peroxisome proliferator-activated receptor \{gamma\} (PPAR\{gamma\}) in liver fibrosis. Am J Physiol Gastrointest Liver Physiol 2006;291:G902-G911.

25. Fukaya $\mathrm{M}$, Isohata $\mathrm{N}$, Ohta $\mathrm{H}$, et al. Hedgehog signal activation in gastric pit cell and in diffuse-type gastric cancer. Gastroenterology 2006;131:14-29.

26. Greenwel P, Schwartz M, Rosas $M$, et al. Characterization of fat-storing cell lines derived from normal and $\mathrm{CCl} 4$-cirrhotic livers. Differences in the production of interleukin-6. Lab Invest 1991;65:644-653.

27. Schaefer B, Rivas-Estilla AM, Meraz-Cruz N, et al. Reciprocal modulation of matrix metalloproteinase-13 and type I collagen genes in rat hepatic stellate cells. Am J Pathol 2003;162:1771-1780.

28. Yahagi $\mathrm{K}$, Ishii $M$, Kobayashi $\mathrm{K}$, et al. Primary culture of cholangiocytes from normal mouse liver. In Vitro Cell Dev Biol Anim 1998;34:512-514.

29. Ishimura N, Bronk SF, Gores GJ. Inducible nitric oxide synthase upregulates Notch-1 in mouse cholangiocytes: implications for carcinogenesis. Gastroenterology 2005;128:1354-1368.

30. Petersen $\mathrm{BE}$, Bowen $\mathrm{WC}$, Patrene $\mathrm{KD}$, et al. Bone marrow as a potential source of hepatic oval cells. Science 1999;284:1168-1170.

31. Ericson J, Morton S, Kawakami A, et al. Two critical periods of Sonic Hedgehog signaling required for the specification of motor neuron identity. Cell 1996;87:661-673.

32. Sicklick JK, Li YX, Choi SS, et al. Role for hedgehog signaling in hepatic stellate cell activation and viability. Lab Invest 2005;85:1368-1380. 
33. Oben JA, Roskams $T$, Yang $S$, et al. Hepatic fibrogenesis requires sympathetic neurotransmitters. Gut 2004;53:438-445.

34. Matsumoto K, Fujii H, Michalopoulos G, et al. Human biliary epithelia cells secrete and respond to cytokines and hepatocyte growth factors in vitro: interleukin-6, hepatocyte growth factor and epidermal growth factor promote DNA synthesis in vitro. Hepatology 1994;20:376-382.

35. Stepan V, Ramamoorthy S, Nitsche $\mathrm{H}$, et al. Regulation and function of the sonic hedgehog signal transduction pathway in isolated gastric parietal cells. J Biol Chem 2005;280:15700-15708.

36. Lewis MT, Veltmaat JM. Next stop, the twilight zone: hedgehog network regulation of mammary gland development. J Mammary Gland Biol Neoplasia 2004;9:165-181.

37. Hanada S, Harada $M$, Koga $H$, et al. Tumor necrosis factor-alpha and interferon-gamma directly impair epithelial barrier function in cultured mouse cholangiocytes. Liver Int 2003;23:3-11.

38. Berman DM, Karhadkar SS, Maitra A, et al. Widespread requirement for Hedgehog ligand stimulation in growth of digestive tract tumours. Nature 2003;425:846-851.

39. Petersen BE, Grossbard B, Hatch $\mathrm{H}$, et al. Mouse A6-positive hepatic oval cells also express several hematopoietic stem cell markers. Hepatology 2003;37:632-640.

40. Mazal PR, Susani M, Wrba F, et al. Diagnostic significance of aquaporin1 in liver tumors. Hum Pathol 2005;36:1226-1231.

41. Fougere-Deschatrette $\mathrm{C}$, Imaizumi-Scherrer T, Strick-Marchand $\mathrm{H}$, et al. Plasticity of hepatic cell differentiation: bipotential adult mouse liver clonal cell lines competent to differentiate in vitro and in vivo. Stem Cells 2006;24:2098-2109.

42. Strick-Marchand H, Weiss MC. Embryonic liver cells and permanent lines as models for hepatocyte and bile duct cell differentiation. Mech Dev 2003;120:89-98.

43. Libbrecht L, Roskams T. Hepatic progenitor cells in human liver diseases. Semin Cell Dev Biol 2002;13:389-396.

44. Steinberg $P$, Weisse $G$, Eigenbrodt $E$, et al. Expression of L- and M2-pyruvate kinases in proliferating oval cells and cholangiocellular lesions developing in the livers of rats fed a methyl-deficient diet. Carcinogenesis 1994;15:125-127.

45. Koenig S, Probst I, Becker $\mathrm{H}$, et al. Zonal hierarchy of differentiation markers and nestin expression during oval cell mediated rat liver regeneration. Histochem Cell Biol 2006;126:732-734.

46. Herrera MB, Bruno S, Buttiglieri $S$, et al. Isolation and characterization of a stem cell population from adult human liver. Stem Cells 2006:24:2840-2850

47. Tee LB, Kirilak Y, Huang WH, et al. Dual phenotypic expression of hepatocytes and bile ductular markers in developing and preneoplastic rat liver. Carcinogenesis 1996;17:251-259.

48. Neumann CJ. Hedgehogs as negative regulators of the cell cycle. Cell Cycle 2005;4:1139-1140.

49. Zhou JX, Jia LW, Liu WM, et al. Role of sonic hedgehog in maintaining a pool of proliferating stem cells in the human fetal epidermis. Hum Reprod 2006;21:1698-1704.

50. Lee $\mathrm{Y}$, Miller HL, Russell HR, et al. Patched2 modulates tumorigenesis in patched 1 heterozygous mice. Cancer Res 2006;66:6964-6971.

51. Uhmann A, Ferch U, Bauer R, et al. A model for PTCH1/Ptch1associated tumors comprising mutational inactivation and gene silencing. Int J Oncol 2005;27:1567-1575.

52. Wetmore C, Eberhart DE, Curran T. The normal patched allele is expressed in medulloblastomas from mice with heterozygous germline mutation of patched. Cancer Res 2000;60:2239-2246.

53. White $\mathrm{AC}, \mathrm{Xu} \mathrm{J}, \mathrm{Yin} \mathrm{Y}$, et al. FGF9 and $\mathrm{SHH}$ signaling coordinate lung growth and development through regulation of distinct mesenchymal domains. Development 2006;133:1507-1517.

54. Zhao R, Duncan SA. Embryonic development of the liver. Hepatology 2005;41:956-967.

55. Shackel NA, McGuinness PH, Abbott CA, et al. Identification of novel molecules and pathogenic pathways in primary biliary cirrhosis: cDNA array analysis of intrahepatic differential gene expression. Gut 2001;49:565-576.

56. Popper H, Kent G, Stein R. Ductular cell reaction in the liver in hepatic injury. J Mt Sinai Hosp NY 1957;24:551-556.

57. Sicklick JK, Li YX, Jayaraman A, et al. Dysregulation of the Hedgehog pathway in human hepatocarcinogenesis. Carcinogenesis 2006;27:748-757.

58. Huang $\mathrm{S}, \mathrm{He} J$, Zhang $\mathrm{X}$, et al. Activation of the hedgehog pathway in human hepatocellular carcinomas. Carcinogenesis 2006;27: 1334-1340.

59. Patil MA, Zhang J, Ho C, et al. Hedgehog signaling in human hepatocellular carcinoma. Cancer Biol Ther 2006;5:111-117.

60. Lowes KN, Brennan BA, Yeoh GC, et al. Oval cell numbers in human chronic liver diseases are directly related to disease severity. Am J Pathol 1999;154:537-541

61. Doles J, Cook C, Shi X, et al. Functional compensation in Hedgehog signaling during mouse prostate development. Dev Biol 2006;295: 13-25.

62. Zhang X, Stappenbeck TS, White AC, et al. Reciprocal epithelialmesenchymal FGF signaling is required for cecal development. Development 2006;133:173-180.

63. Nielsen CM, Williams J, van den Brink GR, et al. Hh pathway expression in human gut tissues and in inflammatory gut diseases. Lab Invest 2004;84:1631-1642.

64. Bataller R, Brenner DA. Liver fibrosis. J Clin Invest 2005;115:209-218.

65. Wells RG, Kruglov E, Dranoff JA. Autocrine release of TGF-beta by portal fibroblasts regulates cell growth. FEBS Lett 2004;559: 107-110.

66. Jhandier MN, Kruglov EA, Lavoie EG, et al. Portal fibroblasts regulate the proliferation of bile duct epithelia via expression of NTPDase2. J Biol Chem 2005;280:22986-22992.

67. Niki T, Pekny M, Hellemans K, et al. Class VI intermediate filament protein nestin is induced during activation of rat hepatic stellate cells. Hepatology 1999;29:520-527.

68. Guma FCR, Mello TG, Mermelstein CS, et al. Intermediate filaments modulation in an in vitro model of the hepatic stellate cell activation or conversion into the lipocyte phenotype. Biochem Cell Biol 2001;79:409-417.

69. Lim YS, Kim KA, Jung JO, et al. Modulation of cytokeratin expression during in vitro cultivation of human hepatic stellate cells: evidence of transdifferentiation from epithelial to mesenchymal phenotype. Histochem Cell Biol 2002;118:127-136.

70. Ramadori G, Saile B. Portal tract fibrogenesis in the liver. Lab Invest 2004:84:153-159.

71. Sicklick JK, Choi SS, Bustamante M, et al. Evidence for epithelialmesenchymal transitions in adult liver cells. Am J Physiol Gastrointest Liver Physiol 2006;291:G575-G583.

72. Dranoff JA, Kruglov EA, Toure J, et al. Ectonucleotidase NTPDase2 is selectively down-regulated in biliary cirrhosis. J Invest Med 2004:52:475-482.

73. Fausto N. Liver regeneration and repair: hepatocytes, progenitor cells, and stem cells. Hepatology 2004:39:1477-1487.

74. Michalopoulos GK, Barua L, Bowen WC. Transdifferentiation of rat hepatocytes into biliary cells after bile duct ligation and toxic biliary injury. Hepatology 2005;41:535-544.

75. Michalopoulos GK, Bowen WC, Mule K, et al. Hepatocytes undergo phenotypic transformation to biliary epithelium in organoid cultures. Hepatology 2002;36:278-283.

76. Fabris L, Strazzabosco M, Crosby HA, et al. Characterization and isolation of ductular cells coexpressing neural cell adhesion molecule and $\mathrm{BCl}-2$ from primary cholangiopathies and ductal plate malformations. Am J Pathol 2000;156:1599-1612.

77. Roskams TA, Theise ND, Balabaud C et al. Nomenclature of the finer branches of the biliary tree: canals, ductules, and ductular reactions in human livers. Hepatology 2004;39:1739-1745. 